\title{
Comparative analysis of peach and nectarine cultivars based on their ecological and biological indicators
}

\author{
Surányi, D. \\ LARIC Fruit Research Station, Cegléd \\ Author for correspondence: suranyi.dezso@cefrucht.hu
}

\begin{abstract}
Summary: Natural conditions other than the ecological conditions of the Chinese gene center (as $34-38^{\circ}$ latitude and 600 to $2400 \mathrm{~m}$ above sea level), mainly dry subtropical, i.e. Mediterranean effects, facilitated the development of new forms and varieties (Scorza \& Okie, 1991; Faust \& Timon, 1995). Probably the primary cause of nectarines, this could also be the primary cause of mutations (probably about 2000 years ago) (Roach, 1985; Surányi, 1985). During the long domestication of peaches, its natural occurrence increased, which was greatly enhanced by its ecological and mutational ability and the organoleptical values of its fruit (Hedrick, 1917; Roach, 1985; Scorza \& Okie, 1991; Faust et al., 2011). Through the Ellenberg-Borhidi model and its refinement, the author has demonstrated the suitability of peaches in a broad climate zone based on the relative ecological and biological values of 700 varieties. Among the varieties, clone cultivars and hybrids were Hungarian selected and crossed form, because the diverse environmental conditions of the Carpathian Basin and the past and present size of cultivation were representative (Faust \& Timon, 1995; Timon, 2000). It can be concluded from the present relative ecological data that the average standard deviation is below $12 \%$ for both peach and nectarine varieties, but the relative biological values were very different. Comparison of cultivars or classical (downy) peaches $(\mathrm{n}=562)$ and nectarines $(\mathrm{n}=138)$ in terms of environmental values confirmed the difference in heat demand and salt tolerance of the two groups of varieties. The pictures of the paper also demonstrated the rich diversity of this fruit species, and after analyzing the apricot and plum varieties (Surányi 2014, 2018), the peculiarities of the relative ecological and biological values of peaches were confirmed.
\end{abstract}

Surányi, D. (2020): Comparative analysis of peach and nectarine cultivars based on their ecological and biological indicators. International Journal of Horticultural Science 26: 7-26. https://doi.org/10.31421/IJHS/26/2020/8006

Key words: peach, nectarine, ecological indicators, biological indicators

\section{Introduction}

The peach is native in the Northwest China between then Tarim Basin and the north of the Kunlun Shan mountains, where it was domesticated and cultivated (Surányi, 1985; Roach, 1985; Scorza \& Okie, 1991; Faust \& Timon, 1995). Fossil endocarps with characteristics indistinguishable from those of modern peaches have been recovered from late Pliocene deposits in Kunming, dating to 2.6 million years ago (Chen, 2015). Dissemination was relatively slow and diverse, geographically, ecologically, and in its changes, creating the potential for diversity. Cultivated peaches are divided into clingstones and freestones, depending on whether the flesh sicks to the stone or not; both can have either white, yellow or purple (Hedrick, 1917; Morettini \& Baldini, 1962; Bordeianu et al., 1967; Soltész, 1998).

In the fruit market is the "traditional peach" (Prunus persica), so the characteristic fuzz on the skin, nectarines (Prunus persica var. nucipersica) are featured by the absence of fruit-skin trichomes (Rehder, 1954; Scorza \& Okie 1991; Faust $\&$ Timon, 1995). The genetic studies provide nectarine are produced due to a recessive allele, whereas peaches are produced from a dominant allele for fuzzy skin (Scorza \& Okie, 1991). It is also believed that the result of the mutation is the socalled flat peaches too (Prunus persica provar. platycarpa) (Terpó, 1974; Faust \& Timon, 1995; Faust et al., 2011). The distribution and production areas of peaches also show the cultivation history itself, given the Linné's variety name circa $2000 \mathrm{BC}$ refers to the region, then they will also begin to be intensively cultivated in China and will be part of the rich
Chinese culture (Roach, 1985; Surányi, 1985; Faust \& Timon, 1995). It then appeared in the Roman Empire, of course in Europe and conquered the overseas territories (Gyulai, 2001; Visy, 2003). The popularity of the species and its cultivation worldwide increases not only breeding activity but also the potential for mutations. Therefore, the start of molecular genetic testing for peaches is an important achievement.

In 2010, the International Peach Genome Initiative (IPGI) published the peach genome sequence and related analyses (Verde et al., 2013).

Peaches grow in quite limited conditions in dry, continental or temperate climates. The reason is that the trees requires chilling that tropical or subtropical areas generally can't satisfy except at high altitudes (Mohácsy et al., 1967; Scorza \& Okie, 1991; Faust et al., 2011). We could not extend order analyzes to the characterization of vegetation, the morphology of the flower, the fruit and the leaf, and even the chemical properties of the fruit and the susceptibility to the individual pathogens, namely the analysis of the Hungarian wild species (Jávorka \& Soó, 1951; Soó, 1964-1985; Zólyomi et al., 1967; Kárpáti \& Terpó, 1971; Kárpáti, 1978; Précsényi, 1986; Zólyomi, 1987; Simon, 1988, 1991), and Raunkiaer forms (1905) and ecological figures of each species (Kovács, 1979; Borhidi, 1993, 1995).

But cultivars and new breeds are what they are. The study presents peaches with relative ecological and biological values, based on the cultivars known in the past, and the differences between the cultivars. The author has analyzed in several studies 
the fruit species, more specifically apricots and plums (Surányi, 2000, 2002, 2006, 2009, 2014, 2015, 2018), considering Ellenberg et al. (1991), Kovács (1979), Simon (1988, 1991) and Borhidi (1993, 1995).

\section{Materials and methods}

There are 700 peach cultivars which have different taxonomic features in studies. These values were determined on the basis of the ecological information of peaches (Hedrick, 1917; Ellenberg, 1950; Rehder, 1954; Fideghelli, 1973; Scorza \& Okie, 1991; Surányi, 1991-2015; Faust \& Timon, 1995; Soltész, 1998, etc.). The definition of Borhidi's ecological figures is following (1993 and 1995). Of the total relative values, only the description of the represented ecological values is always given. The full description can be found in an earlier study (Surányi, 2014), but the abbreviated version was also used below (cf. Surányi 2015 and 2018).

TB: The relative temperature figures reflecting the heat supply of the habitats where the species occur (mainly based on the distribution according to the latitudinal vegetation zones and altitudinal belts). The temperature figures of Ellenberg's (1974) 9-grade scale (T) applied by Borhidi (B) (1995) to the Hungarian flora and by Surányi (2014) to the Hungarian culture's flora. The relative figures indicate the following heat-climate belts or the corresponding microclimate conditions:

5. montane mesophilous broad-leaved forest belt,

6. submontane broad leaved forest belt,

7. thermophilous forest or woodland belt.

WB: The relative moisture figures (occurrence in relation to soil moisture or water table) according to the 12-grade F-scale of Ellenberg (1963). The scale is very similar to the W-scale of Zólyomi (1964), but the water plants have a more detailed categorization, as follows:

4. plants of semidry habitats

5. plants of semi humid habitats, under intermediate conditions

6. plants of fresh soils

RB: Reaction figures, according to the nine-grade Ellenberg's scale (1952), reflect to the occurrence of the plants in relation of the soil reaction of the habitats (Tüxen \& Ellenberg, 1937; Papp \& Tamási, 1979). In the 5-grade Zólyomi's (1987) scale calciphilous and salt tolerant or even halophilous plants are equally treated as basiphilous plants (see Papp \& Tamási, 1979). Here the two groups are differentiated by their positive or negative salt figure category. A comparison of the reaction value scales according to Ellenberg's (1952) versus Zólyomi's classification (1987) was carried out by Pichler \& Karrer (1991). The correspondent degrees are follows:

4. plants of moderately acidic soils

5. plants of slightly acid soils

6. Mostly on neutral soils but also in acid and basic ones, generally widely tolerant, more or less indifferent plants

7. Basifrequent plants, mostly on basic soils.

NB: Nitrogen figures according to Ellenberg's 9-grade scale (1974), based on the occurrence in relation to the ammonia and nitrate supply of the habitats, which received Borhidi (1995) then Surányi (2014) too. These are degrees:

4. Plants of submesotrophic habitats

5. Plants of mesotrophic habitats

6. Plant of moderately nutrient rich habitats.
LB: Light figures according to Ellenberg's 9-grade scale (1974) based on the occurrence of plants in relation to relative light intensity during summer time. Degrees following:

5. Half shadow plants receiving more than $10 \%$ but less than $100 \%$ relative light intensity

6. Half shadow-half light plants; photosynthetic minimum between 10 and $40 \%$ relative light intensity

7. Half light plants, mostly living in full light but also shadow tolerant.

KB: Continentality values according to Ellenberg's nine-grade scale (1952) based on the main distribution of plants according to degree of continentality of the general climate (see Meusel \& Schubert 1972) with emphasis on maximum and minimum temperature. Degrees are follows:

5. intermediate type with slight suboceanic-subcontinental character,

6. subcontinental, main area in eastern Central Europe,

7. continental-subcontinental species main area in EastEurope.

SB: Salt figures for indicating plant occurrence in relation to the salt concentration of the soils in a 9-grade scale, according to Scherfose (1990). Literary sources of ecological indicators are included in the Introduction, because breakdown by type of detail is not possible. The salt figures at least, developed to the SB. The toxic salt content is generally perceived afterwards, when the trees have been damaged:

0 . halophob species not occurring in salty or alkalic soils

1. salt tolerant plants but living mainly on non-saline soils.

It was developing new added relative value numbers that have been introduced in the fruit-bearing species, based on wild species (Iversen, 1936, Tüxen \& Ellenberg, 1937 etc.). We first presented in open pollination, the flower buds and bark frost sensitivity (Kobel, 1954; Porpáczy, 1964; Schwanitz, 1967; Gyuró, 1974 and 1990; Nyéki et al., 1980; Childers \& Sherman, 1988; Nyéki \& Soltész, 1996) and significance for peaches and nectarines main concern viruses Sharka sensitivity (V. Németh, 1986; Papp, 2003, 2004) to disease pathology (taphrina, clasterosporium, monilia) characterization among the peach cultivars (Hedrick, 1917; Tomcsányi, 1960; Knight, 1969; Fideghelli, 1973). The pathological data are new compared to the apricot and plum varieties. The description of the indicator values was the same as the definitions used in our previous studies; see Surányi 2015, 2018).

OP: Measuring of open pollination (Crane \& Lawrence, 1956; McGregor, 1976; Brózik \& Nyéki, 1975; Scorza \& Okie, 1991; Kozma et al., 2003):

1. larger than $35 \%$ of open pollination

2. $20-35 \%$ of open pollination

3. $2-20 \%$ of open pollination

4. $0-2 \%$ of open pollination.

FR: Degree of frost resistance (Kobel 1954; Porpáczy 1964; Larcher 1980; Kozma et al. 2003):

1. frost tolerant (over $5 \%$ of flower bud and bark damage)

2. moderately frost sensitive (15-40\% of damages)

3. frost sensitive (about $50 \%$ of frost damages).

DR: Measuring of disease resistance (namely Taphrina deformans, Clasterosporium carpophyllum, Monilia fruictigena and PPV) (Hedrick, 1917; Tomcsányi, 1979; Scorza \& Okie, 1991; Faust et al., 2011):

1. resistant to disease $(0=$ no symptoms on the trees)

2. moderately sensitive (cc. $30 \%$ of leaves or fruit symptoms)

3. sensitive (over $50 \%$ of leaf symptoms and fruit falling). 
In this study, it was chosen, whether it is possible in an species, though several subtaxa botanical species and under species the representatives of the ecological and biological differences between cultivars characterization according to Ellenberg - Borhidi - Surányi's modified based on the relative figures (Surányi, 2015, 2018). The results are shown in summing of all cultivars of peaches in Table 1 and comparison of peaches ( $\mathrm{n}=512$ and nectarines $(\mathrm{n}=138)$ in Table 2. We assume that the cultivars will be easier of origin and economic-botanical view can be evaluated, increasing the effectiveness of peach and nectarine cultivation.

Criteria were for selecting varieties for analysis and at the same time introduce the most important figures to illustrate the diversity of peach cultivars (Figure 1-12).

1) Well-known variety of properties (Hedrick, 1917; Gardner et al., 1952; Morettini \& Baldini, 1962; Brook \& Olmo, 1972; Fideghelli, 1973; Ninkovski, 1989; Faust, 1989; Faust \& Timon, 1995; Soltész, 1998);

2) varieties known from publications (see above);

3) as far as possible, Hungarian observations (Brózik, 1962

1963; Csöbönyei \& Surányi, 1971-1985; Mándy, 1963; Tomcsányi, 1979; Timon, 1992; G. Tóth, 2001; Pernesz, 2013; Soltész, 2014).

\section{Results and discussion}

The peach is adapted to temperature and subtropical zones, their different forms are one of the very cultivated temperate fruit species. Most commercial production lies between latitudes $30^{\circ}$ and $45^{\circ}$ North and South (Hesse, 1975). Low mid-winter temperatures and spring frost limit peach production in the temperature zone, but the role of diseases and pests and edaphic factors is not insignificant. World production is about 22-24 million tons; the leading growers are China (14.2 Mt), Spain (1.79 Mt), Italy (1.25 Mt), Greece (902 Mt), USA (775 Mt), Turkey (771 Mt), Iran (422 Mt) and Chile 360 Mt). The proportion of downy peaches and nectarines varies from country to country, with the share of nectarines varying from 10 to $65 \%$ (Faust \& Timon, 1995; Surányi, 2018, unpublished).

China as an area of certain species, remains the leading peach growing country; according to China Statistical Yearbook (2016), the top provinces are Shandung (2.94 Mt), Hebei (2.02 Mt), Henar (1.28 Mt) and Shanxi (1.03 Mt). The different peaches spread from China following the trade routes through Persia, along the path of distribution through Europe, adapted population of local peaches can be found, among these are „vineyard" peaches of France, Romania and Hungary (Parnia et al., 1988). These are land races selected for hundreds of years for their productivity and resistance to environmental stress.

Natural conditions other than the ecological conditions of the Chinese gene center (as 34-38 latitude and 600 to $2400 \mathrm{~m}$ above sea level), mainly dry subtropical, i.e. Mediterranean effects, facilitated the development of new forms and varieties (Scorza \& Okie, 1991; Faust \& Timon, 1995). Probably the primary cause of nectarines, this could also be the primary cause of mutations (probably about 2000 years ago) (Roach, 1985; Surányi, 1985). The surface of downy peaches provided greater protection against water drops and various infections, but nectarines were better able to adapt to semi-Mediterranean, Mediterranean conditions. In Hungary, the factors outlined above are less favorable to nectarines than those in Southern Europe, California or China. Examples include the evergreen types in Mexico adapted to very low ,no-chill” areas (Acosta \&
Barrios, 1987), peaches grown by the Navajo Indians in remote areas of Arizona (Jett 1979), and colt-hardy types as 'Bailey' and 'Boone Country' cultivars (Hedrick, 1917).

Peach is closely related to almond and other members of the Amygdalus subgenus. $P$. davidiana, $P$. ferganensis, $P$. kansuensis $P$. mira and $P$. persica - five peach species recognized. Problems of genetic significance are:

a) Climatic adaptations is a function of cold hardiness, chilling requirement, and blossom period once chilling requirement is fulfilled.

b) Cold hardiness: The peach is one least cold tolerant of the commercially grown Prunus species (Quamme et al., 1982). Fully acclimatized peach flower buds can survive $-30{ }^{\circ} \mathrm{C}$ and vegetative buds $-35{ }^{\circ} \mathrm{C}$ (Layne, 1984). Yet, there are genotype that have been consistently shown to have hardy flower buds and/or xylem. Although these genotypes are significantly colder hardy than commercial peach cultivars, some bloom early and as such may be susceptible to spring frosts.

c) Fresh color: freestone cultivars generally have pale yellow flesh and the fruit are harvested when the ground color is green-yellow. A few cultivars develop a bright yellow ground while the fresh is quite firm. Golden yellow or orange flesh, characteristic of several canning clingstone cultivars, adds to the external and internal attractiveness (Scorza \& Okie, 1991).

So there are numerous environmental, health and physiological-cultivation problems: little has been done to select for tolerance to drought and frost.

Table 1 shows the relative ecological and biological values that can be determined from the cultivar descriptions. The values of apricots, plums (Surányi, 2015, 2018) and previously presented with a few representative varieties (Surányi, 2006, 2014) are well connected with the Borhidi's papers (1993, 1995), using experience from other species (Faust \& Surányi, 1997, 1999; Faust et al., 1998; Faust \& Timon, 1995).

It can be concluded from the present relative ecological data that the average standard deviation is below $12 \%$ for both peach and nectarine varieties, but the relative biological values were very different. The Materials and Methods part is based on a large number of sources (Table 1-2). In this study, comparing the respective values of downy and nectarine peaches, we obtained a significant value and, what was striking, the evolution of relative ecological and biological values was harmonious in the comparison between the two groups $(r=+0.8911)$.

Ecological reasons explain the slight differences in the values of the cultivars: the ecogeographical characteristics of the five peach parent (native) species can also be explained by the dislocation of their arable land (Surányi, 1985; Roach, 1985; Scorza \& Okie, 1991; Faust \& Timon, 1995). Attention has been paid to spontaneous form of Hungarian origin, resulting from selection and hybridization. Among the 700 varieties there were 4 cultivar of Hungarian hybrid origin and a further 21 varieties of peaches of Hungarian origin: mutant or result of epigenic stress memory (as Csöbönyei \& Surányi, 1971-1985; Surányi, 1991-2015).

There is no nectarine among the selected cultivars, and among the downy peaches there are a large number of clingstone (on third-part). According to our observations, the frost tolerance of these cultivars was better than that of the seedlingtree Hungarian cultivars. Both in the world and in Hungary, diverse environmental factors have helped to increase the diversity of cultivars. 
Hungarian cultivars and clone varieties were thus as follows, but that does not mean that seedling-trees found in further lands were not: 'Cegléd szépe C. 425', furthermore 'Csizmadia magonca C. 426', 'Homokgyöngye C. 427' and 'Szatymazi Ford' (the last three were not listed in Table 1) (Nyujtó, 1963) However, these have been retained only in home gardens and mostly in traditional vineyards.

The distinction between the types is very difficult, they are referred to as 'Parasztbarack' (peasant peach) most of the time, they were also known on our genebank collection trips, although their value in use was very different (Surányi, 1990): it was suitable for fresh consumption, for drying, for making jam, or for late ripening, high in sugar - It was used as a raw material for wine or brandy. The following are the series of these types of landscapes as local varieties:

\section{a) Hungarian hybrid cultivars $(n=4)$}

'Aranycsillag': Pál Tóth was crossed from American cultivars, matured before Redhaven, freestone.

'Champion type': Hubbard got it from a cross, maturing in early September, freestone.

'Nektár H': a variant of an American variety, matured in front of Redhaven, freestone.

'Remény': It is produced by the crossing, matures in late July, freestone.

\section{b) Spontaneous forms, selected types $(n=21)$}

'Bársonypír': seedling of unknown peach variety, grown in county Csongrád, ripen in early September.

'Cegléd szépe': C. 425 seedling of Sunbeam, maturing in late July, freestone.

'Cserhalmi szépe': of unknown origin, slightly ahead of Champion, freestone.

'Elberta': several of its forms are known in Hungary, ripen in early September, freestone.

'Elvira': ripened in the middle of August, introduced by Sándor Brózik, freestone.

'Ford korai': of American origin, matured in mid-August, semi freestone, known in the Great Hungarian Plain.

'Gyümölcsöskertek királynője': of French origin cultivar, mid to late September ripening, freestone.

'Kecskeméti duránci': János Búzás won from seed, ripens in early September, clingstone

'Kései bronzos Elberta': Gyula Magyar won from Elberta sowing, clingstone, ripens end of September after Elberta.

'Laczy-féle duránci': derivative of an unknown local variety, maturing in the second half of August, clingstone.

'Magyar aranyduráncija': Gyula Magyar selected from Elberta's seedlings, ripens in mid-September, clingstone.

'Mariska': Formed in Buda region, ripening mid-July to early August ripening, freestone.

'Metelka díjazottja': Soma Bartholomoides wins from seed in the 1840s, ripens in late August to early September, freestone.

'Mezőkomáromi duránci': Ferenc Entz won the seed from Ferenc Mayerffy Xavér. They ripen at the end of September, clingstone.

'Paczelt magonca': Selected by János Paczelt from an unknown peach, maturing in early September, freestone.

'Piroska': Under the name C. 2629, its seed was propagated, ripening in mid-late June, and freestone.

'Proskaui': of an unknown cultivar on German region, semi native to Hungary, ripening in late August, freestone.

'Szatymazi Győztes': of unknown origin, ripening in July, more frost tolerant than the basic variety, freestone.
'Szöghi duráncija': József Szöghi is grown from seeds of an unknown cultivar in Szeged, ripens in the 2nd half of September, very bounded to seed, clingstone.

'Vezerle duráncija': It spreads around Balaton, a derivative of the 'Korai hegyi' variety, ripens in August, clingstone

'Vérbarack': Probably from an old Hungarian cultivar, ripened in the last third of September, freestone.

\section{References}

Acosta, F. G., Barrios, E. P. (1987): Effecto de raleo de flor y de fruto sobre el desarrollo de la fruta en el durazno (Prunus persica L. Bartsch). „Siempreverde”Agrociencia 68: 83-92.

Bordeianu, T., Botez, M., Constantinescu, N., Costetchi, M., Cvasniii, D., Demianovici, S., Mihaescu, Gr., Mircea, I., Miron, Gh., Negrilă, A., Oros, F., Petrovici-Birta, I., Pompeius, E., Stefan, N. (1967): Caisul - Persicul. Pomol. Rep. Soc. Rom. V. Edit. Acad. Rep. Soc. Rom., Bucuresti. p. 260610.

Borhidi, A. (1993): A magyar flóra szociális magatartástípusai, természetességi és relatív ökológiai értékszámai. KTM Term. véd. Hiv. Janus Pann. Tud. Egy., Pécs.

Borhidi, A. (1995): Social behaviour types, the naturalness and relative ecological indicator values of the higher plants in the Hungarian flora. Acta Bot. Hung. 39: 97-181.

Brooks, R. M., Olmo, H. P. (1972): Register of new fruits and nut varieties. $2^{\text {nd }}$ ed. Univ. Calif. Pressm Berkeley.

Brózik, S. (1962): Csonthéjastermésűek. Öszibarack. Mezőgazdasági Kiadó, Budapest.

Brózik, S. (1993): Gyümölcsfajták. Mezőgazda Kiadó, Budapest.

Brózik, S., Nyéki, J. (1975): Gyümölcstermő növények termékenyülése. Mezőgazdasági Kiadó, Budapest.

Chen, N, (2015): Oldest peach fossil found in Yunnan. Science Wath 29 (4): 145-146.

Childers, N. F., Sherman, W. B. (1988): The peach. Hortic. Publ., 3906 N. W. 31 Pl., Gainesville, Florida.

China Statistical Yearbook (CSY) (2016): www.stats.gov.cn

Crane, M. B., Lawrence, W. J. C. (1956): The genetics of garden plants. MacMillan Co.Press, London.

Csöbönyei, I., Surányi, D. (1971-1985): Fenológiai naplók (kézirat). Kert. Kut. Int., Cegléd.

Ellenberg, H. (1950): Landwirtschaftliche Pflanzensoziologie I. Unkrautgemeinschaften als Zeiger für Klima und Boden. Ulmer Verlag, Stuttgart.

Ellenberg, H. (1952): Landwirtschaftliche Pflanzensoziologie II. Wiesen und Weiden und ihre standortliche Bewertung. Ulmer Verlag, Stuttgart.

Ellenberg, H. (1963): Ökologische Beiträge zur Umweltgestaltung. Ulmer Verlag, Stuttgart.

Ellenberg, H. (1974): Zeigerwerte der Gefasspflanzen Mitteleuropas. Scripta Geobot. IX. Goltze Verlag, Göttingen.

Ellenberg, H., Weber, H. E., Düll, R., Wirth, W., Werner, W., Paulissen, D. (1991): Zeigeiwerte von Pflanzen in Mitteleuropa. Scripta Geobot. XVIII. Goltze Verlag, Göttingen.

Faust, M. (1989): Physiology of temperate zone fruit trees. J. Wiley and Sons, New York - Chichester - Brisbane - Toronto - Singapure. 
Faust, M., Surányi, D. (1998): Origin and dissemination of cherry. Hort. Rev. N. Y. 19: 263-317.

Faust, M., Surányi, D. (1999): Origin and dissemination of plums. Hort. Rev. N. Y. 23: 179-231.

Faust, M., Surányi, D., Nyujtó, F. (1998): Origin and dissemination of apricot. Hort. Rev. N. Y. 22: 225-266.

Faust, M., Timon, B. (1995): Origin and dissemination of peach. Hort. Rev. N. Y. 17: 331-379.

Faust, M., Surányi, D., Gradziel, T., Timon, B., Nyujtó, F. (ed. Janick, J.) (2011): Origin and dissemination of Prunus. Scripta Horticult. 11: 1-241.

Fideghelli, C. (1973): Manuale di peschicoltura. Edagricola Ed., Bologna.

Gardner, V. R., Bradford, F. Ch., Hooker, H. D. Jr. (1952): The fundamentals of fruit production. McGraw-Hill Book Co., New York - Toronto - London.

G. Tóth, M. (2001): Gyümölcsészet. 2. kiad. Primom Váll. Alap., Nyíregyháza.

Gyulai, F. (2001): Archeobotanika. A kultúrnövények története a Kárpát-medencében a régészeti-növénytani vizsgálatok alapján. Jószöveg Kiadó, Budapest.

Gyuró, F. (ed.) (1974): A gyümölcstermesztés alapjai. Mezőgazdasági Kiadó, Budapest.

Gyuró, F. (ed.) (1990): Gyümölcstermesztés. Mezőgazdasági Kiadó, Budapest.

Hedrick, U. P. (1917): The peaches of New York. N. Y. Sta. Agric. Exp. Sta. 9.

Hesse, C. O. (1975): Peaches. In: J. Janick - J. N. Moore (edits) Advances in fruit breeding. Purdue Univ, Press, West Lefayette, Indiana. p. 285-355.

Iversen, J. (1936): Biologische Pflanzentypen als Hilfsmittel in der Vegetationsforschung. Levin und Munksgaard, Kopenhagen. 224.

Jávorka, S., Soó, R. (1951): A magyar növényvilág kézikönyve I-II. Akadémiai Kiadó, Budapest.

Jett, S. C. (1979): Peach cultivation and use among the Canyon de Chelly Navajo. Ecol. Bot.33: 298-310.

Kárpáti, I. (1978): Magyarországi vizek és ártéri szintek növényfajainak ökológiai besorolása. Keszth. Agrártud. Egyet. Kiadv. 20: 5-62.

Kárpáti, Z., Terpó, A. (1971): Alkalmazott növényföldrajz. Mezőgazdasági Kiadó, Budapest.

Knight, R. L. (1969): Abstract bibliograhy of fruit breeding and genetics to 1965. Prunus. Comm. Agric. Bur. (CAB), East Malling.

Kobel, F. (1954): Lehrbuch des Obstbaus auf phsiologischer Grundlage. Springer Verlag, Berlin.

Kovács, J. A. (1979): Indicatorii biologici, ecologici si economici ai florei pajistilor. Minist. Agricult. si Ind. Aliment., Bucuresti.

Kozma, P., Nyéki, J., Soltész, M., Szabó, Z. (ed.) (2003): Floral biology, pollination and fertilisation in temperate zone fruit species and grape. Akadémiai Kiadó, Budapest.

Larcher, W. (1980): Physiological plant ecology. Springer Verlag, Berlin - Heidelberg - New York.
Layne, R. E. C. (1984): Breeding peaches in North America for cold hardiness an perennial cancer of peach (Leucostoma spp.) resistance. - Review and outlook. Fruit Var. J. 38: 130-136.

Mándy, Gy. (1963): Kertészeti növények nemesítése táblázatokban. Mezőgazdasági Kiadó, Budapest.

McGregor, S. E. (1976): Insect pollination of cultivated crop plants. U.S. Dept. Agric.,Washington.

Meusel, H., Schubert, R. (1972): Volk und Wissen. Akademie Verlag, Berlin.

Mohácsy M., Maliga P., Mohácsy M. (1967): Az őszibarack. Mezőgazdasági Kiadó, Budapest.

Morettini, A., Baldini, E. (1962): Monografia delle principali cultivar di pesco. Riv. Ortoflorofruttic. Ital. 24 (1): 3-44.

Ninkovski, I. (1989): Nektarin, a sima héjú őszibarack. Mezőgazdasági Kiadó, Budapest.

Nyéki, J. (ed.) (1980): Gyümölcsfajták virágzásbiológiája és termékenyülése. Mezőgazdasági Kiadó, Budapest.

Nyéki, K., Soltész, M. (ed.) (1996): Floral biology of temperate zone fruit trees and small fruits. Akadémiai Kiadó, Budapest.

Nyujtó, F. (1963): Az alföldi őszibaracktermesztés. In: Mohácsy M., Maliga P., Mohácsy, M. (1967): Az őszibarack. Mezőgazdasági Kiadó, Budapest. 457-469. p.

Papp, J. (ed.) (2003): Gyümölcstermesztési alapismeretek. Mezőgazda Kiadó, Budapest.

Papp, J. (ed.) (2004): A gyümölcsök termesztése. Mezőgazda Kiadó, Budapest.

Papp, J., Tamási, J. (1979): Gyümölcsösök talajművelése és tápanyagellátottsága. Mezőgazdasági Kiadó, Budapest.

Parnia, P., Mladin, Gh., Dutu, I., Stanciu, N. (1988): Progress in breeding rootstocks in Roumania. HortSci. N. Y. 23:107-109.

Pernesz, Gy. (2013): Nemzeti fajtajegyzék - National list of varieties. Gyümölcs - Fruit. NÉBIH, Budapest. ISSN 15858308

Pichler, F., Karrer, G. (1991): Comparison of different ecological indicator value systems. In: Horváth, F. (ed.): Poster Abstracts 34th IAVS Symposium, Eger, Hungary. p. 102-104.

Porpáczy, A. (ed.) (1964): A korszerü gyümölcstermesztés elméleti kérdései. Mezőgazdasági Kiadó, Budapest.

Précsényi, I. (1986): The acoluthic space and its importance in the ecologicai research. Acta Bot. Hung. 32: 53-60.

Quamme, H. A., Layne, R. E. C., Ronald, W. G. (1982): Relationship of super-cooling to cold hardiness and the northern distribution of several cultivated and native Prunus species and hybrids. Can. J. Plant Sci. 62: 137-148.

Raunkiaer, C. (1905): Types biologiques pour la géographie botanique. Oversigt over Det Kongel. Danske Videnskab. Selsk. Forhandl. p. 347-438.

Rehder, A. I. (1954): Manual of cultivated trees and shrubs. McMillan Ed., New York

Roach, F. A. (1985): Cultivated fruits of Britain. Their origin and history. Basil Blackwill Public. Ltd., Oxford - New York.

Scherfose, V. (1990): Salz-Zeigerwerte von Gefásspflanzen der Salzmarschen Tideröhrichte und Salzwassertümpel an der deutschen Nord- und Ostseeküste. Jb. Nieders. Landesamt Wasser und Abfall, Forsch. stelle Küste 39: 31-82. 
Schwanitz, F. (1973): A kultúrnövények keletkezése: az egész növényvilág evolúciós modellje. Mezőgazdasági Kiadó, Budapest.

Scorca, R., Okie, W. R. (1991): Peaches (Prunus). in: Genetic recources of temperature fruit and nut crops vol. I-II. eds. Moore, J. N. -Ballington, R, Jr. ISHS, Wageningen. 177-231.

Shahbandeh, M. (2017): Global production of fruit bay variety. https//www.statista.com.

Simon, T. (1988): A hazai edényes flóra természetvédelmi érték-besorolása. Abstr. Bot. 2: 1-23.

Simon, T. (1991): A magyarországi edényes flóra határozója (Harasztok - Virágos növények). Nemzeti Tankönyvkiadó, Budapest.

Soltész, M. (ed.) (1998): Gyümölcsfajta-ismeret és-használat. Mezőgazda Kiadó, Budapest.

Soltész, M. (ed.) (2014): Magyar Gyümölcsfajták. Mezőgazda Kiadó, Budapest.

Soó, R. (1964-1985): A magyar flóra és vegetáció rendszertaninövényföldrajzi kézikönyveI-VII. köt. Akadémiai Kiadó, Budapest.

Surányi, D. (1985): Kerti növények regénye. Mezőgazdasági Kiadó, Budapest.

Surányi, D. (1990): Az alföldi szőlők és szórványgyümölcsösök pomológiai értékei. Kertgazdaság 22 (6): 45-63.

Surányi, D. (1991-2015): Fenológiai naplók (kézirat). Gyümölcskut. Áll. Kft, Cegléd.

Surányi, D. (2000): A termesztett gyümölcsfajok-és fajták ökológiai sajátosságai, azok besorolása a Simon-féle értékszámok szerint. Acta Biologica Debrecina 11 (1): 143.

Surányi, D. (2002): Gyümölcsöző sokféleség (Biodiverzitás a gyümölcstermesztésben). Akcident Kft., Cegléd.

Surányi, D. (2006): Magyarország gyümölcs-flórájának biológiai-ökológiai jellemzése. (Hazai vadon termő, meghonosodott, elvadult és potenciális gyümölcsfajok, valamint termesztett gyümölcsfajták értékelése). Kanitzia 14: 137-206.

Surányi, D. (2009): Lépcsőfokok - Értekezések a gyümölcstermesztés köréből. GyDKFI, Cegléd.

Surányi, D. (2014): Relative eclogical indicators of the registrated and old historical fruit cultivars in Hungary. Acta Bot. Hung. 56 (3-4): 433-484. https://doi.org/10.1556/ ABot.56.2014.3-4.16
Surányi, D. (2015): Relative ecological and biological indicator values of plum and prune cultivars. Intern. J. Hort. Sci. 21 (3-4): 376-53. https://doi.org/10.31421/IJHS/21/3-4./1173

Surányi, D. (2018): Comparative analysis of apricot cultivars based on their ecological and biological indicators. Intern. J. Hort. Sci. (2016) 22 (1-4): 35-50. https://doi.org/10.31421/ IJHS/22/3-4./1190

Terpó, A. (1974): Gyümölcstermő növényeink rendszertana és földrajza. In: Gyuró, F. (edit.) A gyümölcstermesztés alapjai. Mezőgazdasági Kiadó, Budapest. 139-219.

Timon, B. (1992): Öszibarack. 3. kiad. Mezőgazda Kiadó, Budapest.

Tomcsány, P. (1960): Gyümölcsfajták irodalmi vonatkozásai (témadok.). Agroinform, Budapest.

Tomesányi, P. (ed.) (1979): Gyümölcsfajtáink. Gyakorlati pomológia. Mezőgazdasági Kiadó, Budapest.

Tüxen, R., Ellenberg, H. (1937): Die systematische und ökologische Gruppenwer. Mitt. flor.-soz. Arbeuitsgem. Niedersachsen 3: 171-184.

Verde, I., Verde, A. G., Abbott, S., Scalabrin, S., Jung, S. Shu, F., Marroni, F., Zhebentyayaeva, M. T., Dettri, J., Grimwood, F., Cattonaro, A., Zuccol, L., Rossini, J., Jenkins, E., Vendramin, L. A., Meisel, V., Decroocq, B., Sosinsli, S., Prochnik, T., Mitros, A., Policriti, G., Ciprioani,L., Dondini, S., Ficklin, D. M., Goodstein, P., Xuan, C. D., Del Fabbro, V., Aramini, D., Copetti, S., Gonzales, D. S. (2013): The high-quality draft genome of peach (Prunus persica) identifies unique patterns of genetic diversity, domestication and genome evolution. Nature Genetic 45 (5): 487-494. https://doi.org/10.1038/ng.2586

Visy, Zs. (ed.) (2003): Magyar régészet az ezredfordulón. NKÖM Teleki László Alapítvány, Budapest.

V. Németh, M. (1986): The virus, mycoplasma and rickettsia diseases of fruit trees. Akadémiai Kiadó, Budapest.

Zólyomi, B. (1964): Methode zur ökologischen Characterisierung der Vegetation seinheiten und zum Vergleich der Standorte. Mathematisch-statistische Bearbeitung der Beispiele von I. Précsényi. Acta Bot. Hung. 10: 377-416.

Zólyomi, B. (1987): Coenotone, ecotone and their role in the preservation of relic species. Acta Bot. Hung. 33: 3-18.

Zólyomi, B., Baráth, Z., Fekete, G., Jakucs, P., Kárpáti, I., Kárpáti, V., Kovács, M., Máthé, I. (1967): Einreihung von 1400 Arten der ungarischen Flora in ökologischen Gruppen nach TWR-Zahlen. Fragmenta Bot. Mus. Hist. Nat. Hung. 4: 101142. 

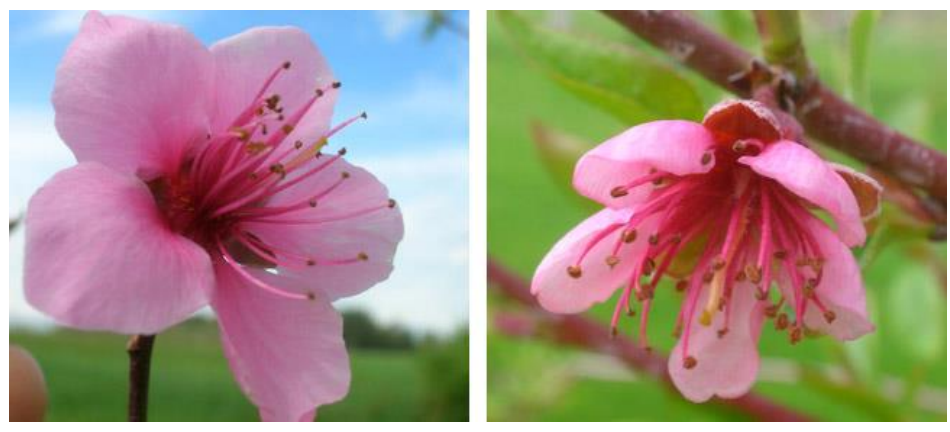

Figure 1. Rose and bell flower of peach

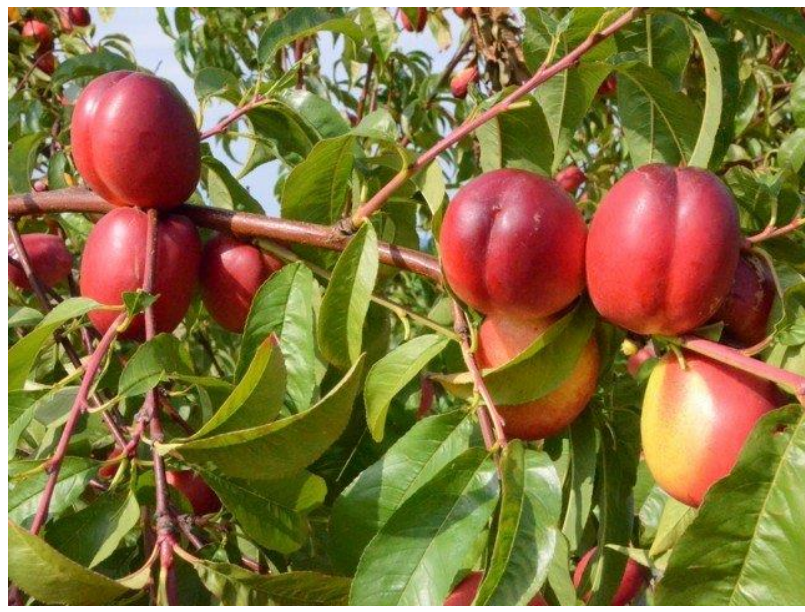

Figure 3. Nectarine fruits

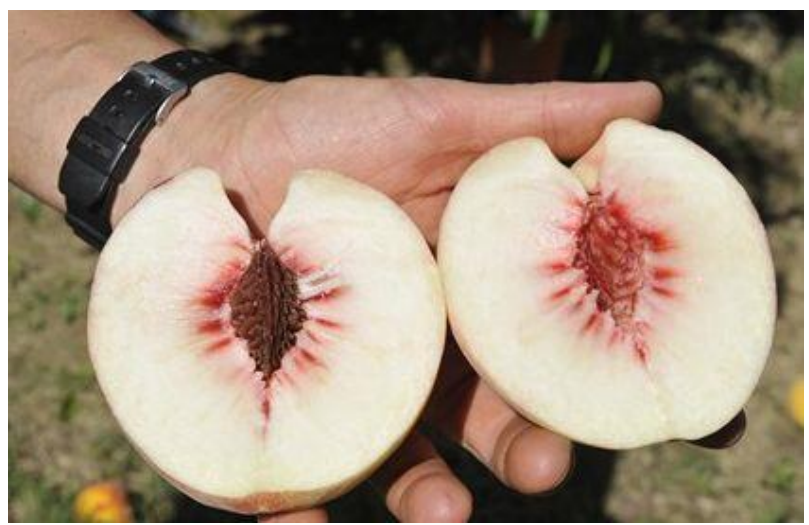

Figure 5. Of white flesh fruit

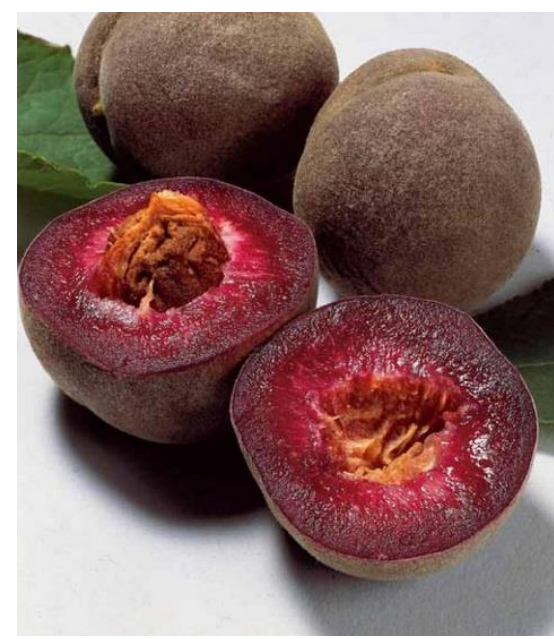

Figure 7. Of blood fruit peach

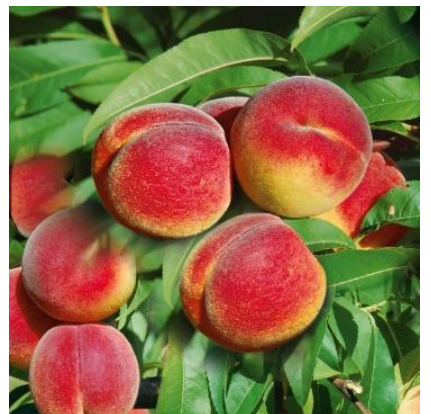

Figure 2. Downy fruits

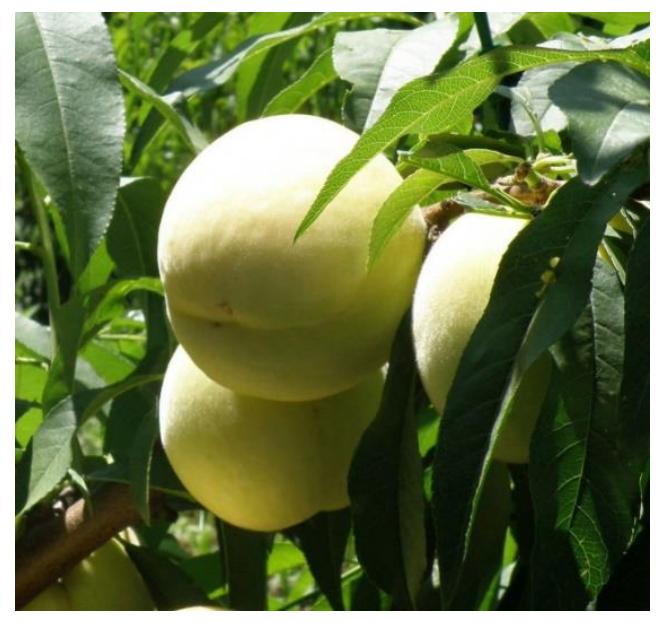

Figure 4. Snow white peach

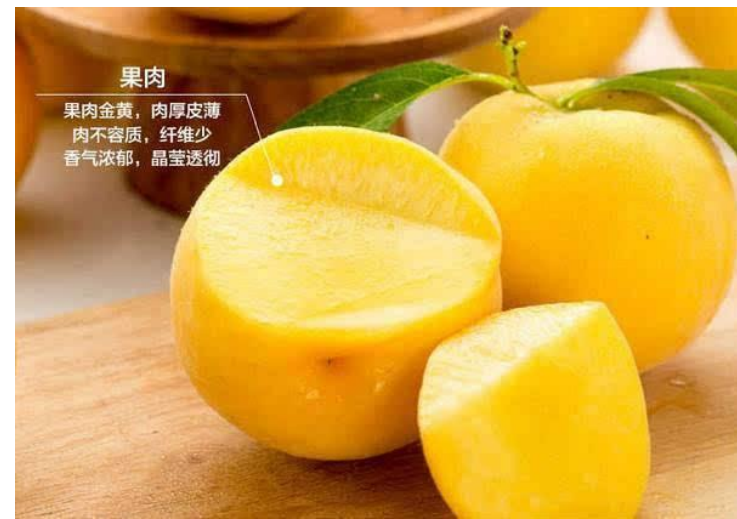

Figure 6. Of yellow flesh fruit

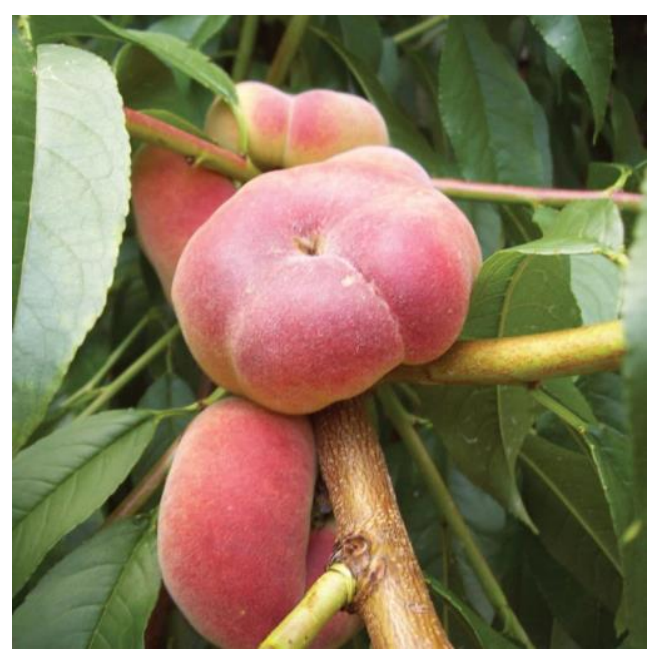

Figure 8. Flat peach 


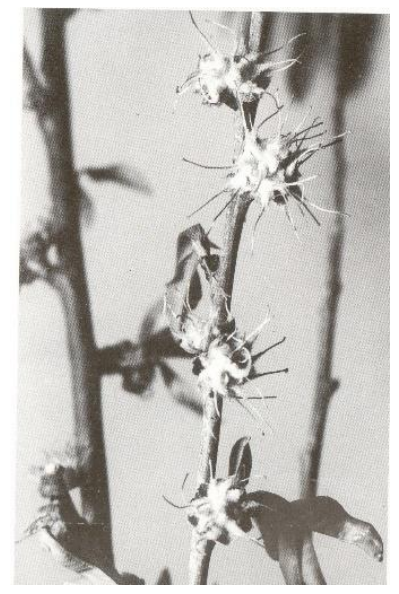

Figure 9. Peach chimera (bare flowers)

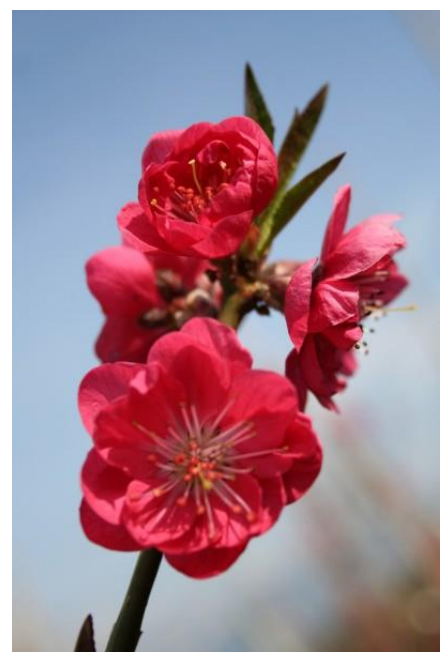

Figure 11. Ornamental peach twig

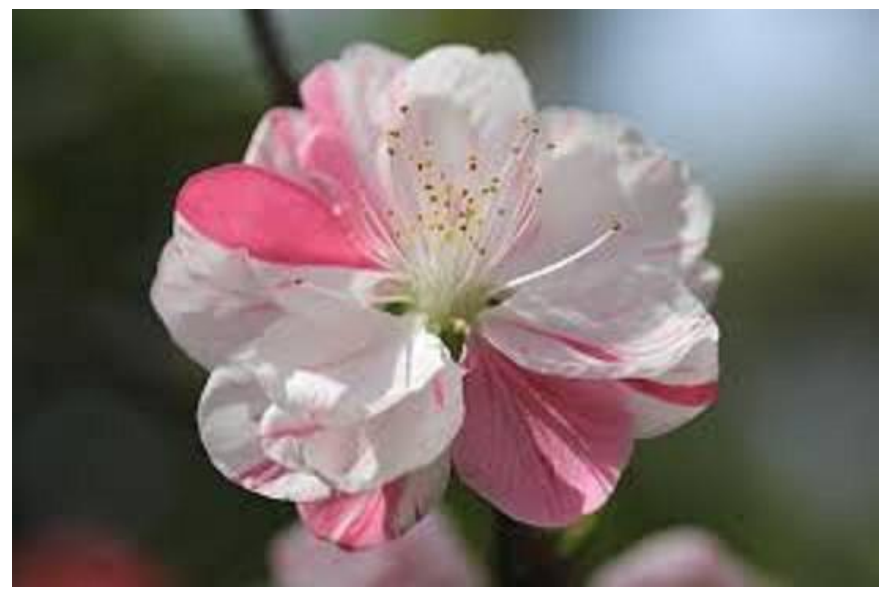

Figure 10. With colored petals

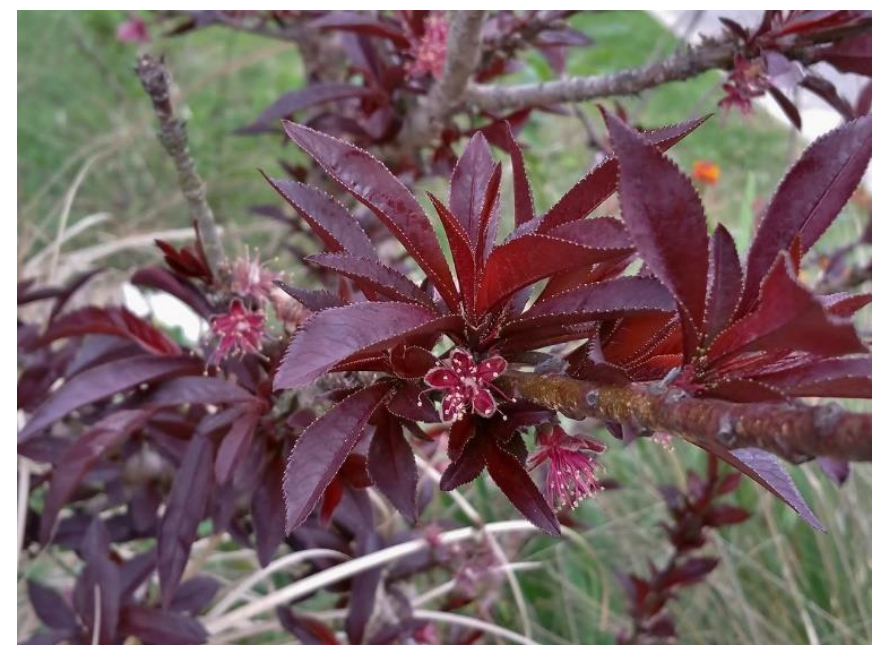

Figure 12. Of purple leaf peach

Table 1. Relative ecological and biological indicator values of each cultivars $(\mathrm{n}=700)$

\begin{tabular}{|l|c|c|c|c|c|c|c|c|c|c|}
\hline CULTIVARS & TB & WB & RB & NB & LB & KB & SB & OP & FR & DR \\
\hline Abricotée de Gien & 5 & 5 & 6 & $4-5$ & $5-6$ & 6 & 0 & 2 & $1-2$ & 1 \\
\hline Admirable & $5-6$ & 5 & 5 & 5 & $5-6$ & $5-6$ & 0 & $1-2$ & $1-2$ & 2 \\
\hline Admirable Jaune & 5 & $4-5$ & $6-7$ & $4-5$ & 5 & $6-7$ & 0 & 3 & 2 & 2 \\
\hline Admiral Dewey & 6 & 5 & 6 & 5 & 5 & $5-6$ & 0 & 2 & $1-2$ & 1 \\
\hline Adriana & 5 & 5 & 6 & 5 & $5-6$ & $6-7$ & 0 & 2 & 2 & 2 \\
\hline Advence & $5-6$ & 5 & 6 & 5 & $5-6$ & 6 & 0 & $2-3$ & 2 & $1-2$ \\
\hline Alberge & 5 & 5 & $5-6$ & 5 & 6 & $5-6$ & 0 & $2-3$ & 2 & 2 \\
\hline Alexander & $5-6$ & $4-5$ & $6-7$ & 5 & 5 & 6 & 0 & $2-3$ & $1-2$ & 2 \\
\hline Alton & $5-6$ & $4-5$ & $6-7$ & $4-5$ & $5-6$ & 6 & 0 & $2-3$ & $1-2$ & 2 \\
\hline Amador & 6 & 5 & $6-7$ & $4-5$ & 5 & $6-7$ & 0 & $1-2$ & 2 & 2 \\
\hline Amelia & $5-6$ & 5 & $5-6$ & 5 & $5-6$ & $5-6$ & 0 & $1-2$ & $1-2$ & 2 \\
\hline Ameliaberta & $6-7$ & 5 & 6 & $4-5$ & 6 & 6 & 0 & 2 & 2 & 2 \\
\hline Amsden & $5-6$ & $4-5$ & 6 & $4-5$ & $5-6$ & 6 & 0 & $1-2$ & 2 & 2 \\
\hline Andosa & 6 & 5 & 6 & 5 & 6 & 6 & 0 & $1-2$ & 2 & 2 \\
\hline Annbella & $6-7$ & 5 & $6-7$ & 5 & 6 & $6-7$ & 0 & $2-3$ & 2 & 2 \\
\hline Anza & 6 & 5 & 6 & 5 & 5 & 6 & 0 & 2 & $2-3$ & 2 \\
\hline Apolka & $5-6$ & 5 & 6 & 5 & $5-6$ & 6 & 0 & 2 & $1-2$ & $1-2$ \\
\hline Arany csillag & 6 & 4 & $6-7$ & 5 & $5-6$ & $6-7$ & $0-1$ & 2 & 1 & $1-2$ \\
\hline Armking & $5-6$ & 5 & 6 & 5 & 5 & 6 & 0 & $2-3$ & 2 & $2-3$ \\
\hline Armred & $5-6$ & $4-5$ & 6 & 5 & 5 & 6 & 0 & 2 & $2-3$ & 2 \\
\hline Arp Beauty & 6 & 5 & 6 & 5 & $5-6$ & $6-7$ & 0 & 3 & 2 & 2 \\
\hline Babygold 5 & 6 & $4-5$ & $6-7$ & $4-5$ & $5-6$ & 6 & 0 & 2 & 2 & $1-2$ \\
\hline & & & & & & & \\
\hline
\end{tabular}




\begin{tabular}{|c|c|c|c|c|c|c|c|c|c|c|}
\hline Babygold 6 & 6 & $4-5$ & $6-7$ & $4-5$ & $5-6$ & 6 & 0 & 2 & 2 & $1-2$ \\
\hline Babygold 7 & 6 & $4-5$ & 7 & $4-5$ & $5-6$ & 6 & 0 & 2 & $2-3$ & 2 \\
\hline Babygold 8 & $5-6$ & $4-5$ & $6-7$ & $4-5$ & $5-6$ & 6 & 0 & 2 & $1-2$ & $1-2$ \\
\hline Babygold 9 & $5-6$ & $4-5$ & 6 & $4-5$ & 6 & 5 & 0 & 2 & 2 & $1-2$ \\
\hline Baden Schöne & 6 & 5 & 6 & 6 & 6 & 5 & 0 & $2-3$ & 2 & 2 \\
\hline Baladin & $5-6$ & $4-5$ & 6 & 5 & 5 & 6 & 0 & $1-2$ & 2 & 3 \\
\hline Balkonella & 5 & 4 & 6 & $4-5$ & 5 & 6 & $0-1$ & 3 & 2 & 2 \\
\hline Banner & 5 & $4-5$ & 6 & $4-5$ & 5 & 6 & 0 & $2-3$ & $2-3$ & 1 \\
\hline Barber & $5-6$ & $4-5$ & $5-6$ & $4-5$ & $5-6$ & $5-6$ & $0-1$ & 2 & 2 & 2 \\
\hline Barrington & $5-6$ & 5 & 6 & 5 & $5-6$ & 6 & 0 & $2-3$ & $1-2$ & $1-2$ \\
\hline Bársonypír & 6 & 4 & 6-7 & 5 & $5-6$ & $6-7$ & 0 & 2 & $1-2$ & $1-2$ \\
\hline Bartet & $5-6$ & $4-5$ & 6 & $4-5$ & $5-6$ & 6 & 0 & $3-4$ & 2 & 2 \\
\hline Belle & 5 & $4-5$ & 6 & $4-5$ & 5 & $5-6$ & 0 & $1-2$ & 2 & $1-2$ \\
\hline Belle de Cap & $5-6$ & 5 & 6 & 5 & $5-6$ & 6 & 0 & $1-2$ & $1-2$ & 2 \\
\hline Belle de Toulouse & $6-7$ & 5 & 6 & 5 & 6 & 6 & $0-1$ & 1 & $1-2$ & 2 \\
\hline Berenice & $5-6$ & 5 & $6-7$ & 5 & $5-6$ & $5-6$ & 0 & 2 & $1-2$ & $1-2$ \\
\hline Biancona de Verona & 5 & $4-5$ & 6 & 5 & 5 & 6 & 0 & 3 & 2 & $1-2$ \\
\hline Big Top & 5 & 5 & 6 & 5 & $5-6$ & $5-6$ & 0 & $2-3$ & 2 & $2-3$ \\
\hline Blazing Gold & $5-6$ & $4-5$ & $6-7$ & $4-5$ & $5-6$ & 6 & 0 & $2-3$ & 2 & 2 \\
\hline Blood Cling & 6 & 5 & 6 & 5 & 5 & $5-6$ & 0 & 3 & 2 & 2 \\
\hline Blood Leaf & $5-6$ & $4-5$ & 5 & $4-5$ & 5 & $5-6$ & 0 & $2-3$ & 2 & $1-2$ \\
\hline Bokhara & 7 & 5 & 6 & 5 & $5-6$ & 6 & 0 & $1-2$ & $2-3$ & 1 \\
\hline Bonanza & 5 & 4 & 6 & $4-5$ & $5-6$ & $5-6$ & $0-1$ & $2-3$ & $2-3$ & 2 \\
\hline Bordeaux & 6-7 & 5 & 6 & 5 & 6 & 6 & 0 & 2 & 2 & 2 \\
\hline Bourdin & 6 & $4-5$ & 6 & 5 & 5 & $6-7$ & 0 & 3 & $1-2$ & 2 \\
\hline Brackett & $5-6$ & 5 & 6-7 & $4-5$ & $5-6$ & 6 & 0 & $2-3$ & 2 & 2 \\
\hline Briggs & $5-6$ & $4-5$ & $5-6$ & $4-5$ & $5-6$ & 6 & 0 & $1-2$ & 2 & 2 \\
\hline Brilliant & 5 & 5 & $5-6$ & 5 & 5 & $5-6$ & 0 & 2 & 2 & $1-2$ \\
\hline Brunson & 5 & $4-5$ & 5 & $4-5$ & 5 & 6 & 0 & 3 & $1-2$ & 2 \\
\hline Buquette Free & 6 & 5 & 6 & 5 & $5-6$ & 6 & 0 & $2-3$ & 2 & 2 \\
\hline Buttercup & 5 & $4-5$ & 5 & $4-5$ & 5 & 5 & $0-1$ & $1-2$ & 2 & $1-2$ \\
\hline Caffey & 6 & 5 & $6-7$ & 5 & $5-6$ & 6 & 0 & 1 & 2 & $1-2$ \\
\hline Canada & $5-6$ & 5 & 6 & 5 & 5-6 & 6 & 0 & $1-2$ & $1-2$ & $1-2$ \\
\hline Cancellar & $5-6$ & 5 & 6 & 6 & 5-6 & 6 & 0 & $2-3$ & 2 & 2 \\
\hline Capps & $5-6$ & 5 & $5-6$ & 5 & $5-6$ & 5 & $0-1$ & 2 & 2 & $2-3$ \\
\hline Captain Ede & $5-6$ & $4-5$ & 6 & $4-5$ & $5-6$ & 5 & 0 & 3 & $1-2$ & 2 \\
\hline Capuzzi No. 1 & 6 & 5 & 6 & 5 & 5 & $6-7$ & 0 & $1-2$ & 2 & 1 \\
\hline Cardinal & 6 & 4 & 6 & 5 & $5-6$ & 6 & 0 & $2-3$ & $1-2$ & 2 \\
\hline Carman & 7 & 5 & $6-7$ & $4-5$ & 6 & $6-7$ & 0 & $1-2$ & 1 & 1 \\
\hline Catharine & $5-6$ & $4-5$ & 5 & $4-5$ & $5-6$ & $5-6$ & 0 & 2 & $1-2$ & 2 \\
\hline Cavaller & $6-7$ & 5 & 6 & 5 & $5-6$ & 6 & 0 & 2 & 2 & 2 \\
\hline Cegléd szépe & $5-6$ & 5 & $6-7$ & 5 & $5-6$ & 6 & 0 & $1-2$ & 3 & 2 \\
\hline Champion & $5-6$ & $4-5$ & 7 & $4-5$ & $5-6$ & 6 & 0 & $1-2$ & $1-2$ & 2 \\
\hline Chazotte & $6-7$ & 5 & 6 & 6 & $5-6$ & $6-7$ & 0 & 2 & 3 & 2 \\
\hline Cherryred & $5-6$ & $4-5$ & $5-6$ & 5 & 5 & 6 & 0 & $1-2$ & 2 & 2 \\
\hline Chinese Cling & 6 & 5 & $6-7$ & $4-5$ & $5-6$ & 6 & 0 & $1-2$ & 1 & $1-2$ \\
\hline Clarissa & $6-7$ & 5 & $6-7$ & 5 & $5-6$ & 6 & 0 & $2-3$ & 3 & 2 \\
\hline Climax & 6 & 5 & 6 & 5 & $5-6$ & $5-6$ & $0-1$ & 1 & $1-2$ & 2 \\
\hline Collins & $5-6$ & $4-5$ & 6 & $4-5$ & 5 & 6 & 0 & 2 & $1-2$ & 1 \\
\hline Comanche & 6 & 5 & 6 & 5 & $5-6$ & 5 & 0 & 2 & 1 & 2 \\
\hline Compact Redhaven & $6-7$ & 5 & 6 & 5 & $5-6$ & 6 & $0-1$ & $2-3$ & 2 & $2-3$ \\
\hline Condor & $5-6$ & 5 & 6 & 5 & 5 & 6 & 0 & $1-22$ & $1-2$ & 2 \\
\hline Coronado & 6 & $4-5$ & $6-7$ & $4-5$ & $5-6$ & $6-7$ & 0 & $2-3$ & 2 & $1-2$ \\
\hline Coronet & $6-7$ & 5 & 6 & 5 & $5-6$ & 6 & 0 & 2 & 2 & 2 \\
\hline Cote d'Azur & 7 & 5 & $6-7$ & 5 & 6 & 6 & $0-1$ & $3-4$ & 3 & 2 \\
\hline Cresthaven & $5-6$ & $4-5$ & 6 & $4-5$ & $5-6$ & 6 & 0 & 2 & $1-2$ & $2-3$ \\
\hline Crosby & $5-6$ & 5 & 6 & $5-6$ & 5 & 6 & 0 & $2-3$ & $1-2$ & 2 \\
\hline Crown Princess & 6 & $4-5$ & 6 & 5 & $5-6$ & 5 & 0 & 2 & $1-2$ & $1-2$ \\
\hline Cuirlew & $5-6$ & 5 & 5 & 5 & 5 & 6 & 0 & 2 & $2-3$ & 2 \\
\hline Culemborg & 5 & $4-5$ & $5-6$ & 5 & 5 & $5-6$ & 0 & $1-2$ & $1-2$ & 1 \\
\hline
\end{tabular}




\begin{tabular}{|c|c|c|c|c|c|c|c|c|c|c|}
\hline Cserhalmi szépe & 6 & $4-5$ & 6 & 5 & $5-6$ & 6 & 0 & $2-3$ & $1-2$ & $1-2$ \\
\hline Demeure & 6 & 5 & 6 & 5 & $5-6$ & $6-7$ & 0 & 3 & 3 & 1 \\
\hline Demuilles & $5-6$ & $4-5$ & $5-6$ & $4-5$ & 5 & 5 & 0 & $2-3$ & 2 & 2 \\
\hline Dixigem & 6 & $4-5$ & $6-7$ & $4-5$ & 5 & 6 & 0 & $2-3$ & $1-2$ & 3 \\
\hline Dixired & 6 & 4 & 7 & $4-5$ & 5 & 6 & 0 & 2 & 2 & 2 \\
\hline Dr. Burton & 5 & 5 & $5-6$ & $4-5$ & $5-6$ & 5 & 0 & $1-2$ & 2 & 2 \\
\hline Dulce & $5-6$ & 5 & 6 & 5 & 6 & 6 & 0 & 2 & 1 & $1-2$ \\
\hline EarliGlo & $5-6$ & $4-5$ & 6 & 5 & $5-6$ & 6 & 0 & 2 & $1-2$ & 2 \\
\hline Earlired & $5-6$ & $4-5$ & $6-7$ & 5 & $5-6$ & $6-7$ & 0 & 2 & 1.2 & $1-2$ \\
\hline Early China & $5-6$ & $4-5$ & $5-6$ & $4-5$ & 5 & $5-6$ & 0 & $2-3$ & $1-2$ & 2 \\
\hline Early Crawford & $5-6$ & $4-5$ & 6 & 5 & 5 & 6 & 0 & 2 & 2 & 2 \\
\hline Early East & 6 & 5 & 6 & 5 & $5-6$ & 6 & 6 & 1 & 2 & 2 \\
\hline Early Elberta & $5-6$ & 4 & $6-7$ & $4-5$ & 5 & 6 & 0 & 1 & 2 & 2 \\
\hline Early Michigan & 6 & 5 & 6 & 5 & 5 & 6 & 0 & 1 & $1-2$ & 2 \\
\hline Early Mignon & $5-6$ & 5 & 6 & 5 & $5-6$ & 6 & 0 & 2 & 2 & 2 \\
\hline Early Red Free & 6 & 4 & 6 & $4-5$ & 5 & $6-7$ & 0 & 1 & $1-2$ & 2 \\
\hline Early Redhaven & $5-6$ & $4-5$ & $6-7$ & 5 & $5-6$ & 6 & 0 & 2 & 2 & $1-2$ \\
\hline Early Victoria & 5 & $4-5$ & 5 & $4-5$ & $5-6$ & 6 & 0 & 2 & 2 & 1 \\
\hline Early White Giant & 5 & 4 & 6 & 5 & 5 & $6-7$ & 0 & 1 & 2 & 2 \\
\hline Earlycrest & 5 & $4-5$ & 6 & 5 & $5-6$ & 6 & 0 & $1-2$ & $1-2$ & $1-2$ \\
\hline Earlyvee & $5-6$ & 5 & 6 & 5 & $5-6$ & 6 & 0 & 2 & $1-2$ & 1 \\
\hline Eclispe & 5 & 4 & 6 & 5 & $5-6$ & 6 & $0-1$ & $1-2$ & 2 & 2 \\
\hline Elberta & $5-6$ & $4-5$ & 7 & 4 & 5 & $5-6$ & $0-1$ & $1-2$ & $2-3$ & $1-2$ \\
\hline Elegant Lady & 5 & 5 & 6 & 5 & $5-6$ & 5 & 0 & $2-3$ & 2 & 2 \\
\hline Elvira & $5-6$ & $4-5$ & $6-7$ & $4-5$ & 5 & 5 & 0 & 2 & $1-2$ & 2 \\
\hline Eve & 5 & $4-5$ & $5-6$ & 5 & 5 & $5-6$ & 2 & 2 & 2 & 2 \\
\hline Evelyn Gem & 5 & 5 & 6 & 5 & 6 & $5-6$ & 0 & $2-3$ & 2 & 2 \\
\hline Everts & $5-6$ & 5 & 6 & 5 & $5-6$ & $5-6$ & 0 & $2-3$ & 2 & 2 \\
\hline Excellencs & 6 & 5 & 6 & 5 & 6 & $5-6$ & 0 & 1 & 2 & 2 \\
\hline Fairhaven & 6 & $4-5$ & 6 & 5 & 6 & $5-6$ & 0 & 1 & $1-2$ & 3 \\
\hline Fairlane & 7 & 5 & 6 & 5 & 6 & 6 & 0 & 2 & 2 & 1 \\
\hline Fantasia & $6-7$ & $4-5$ & 7 & 5 & 6 & 5 & 0 & 2 & 2 & 2 \\
\hline Fayette & 6 & 5 & 6 & $4-5$ & 6 & 6 & 0 & $1-2$ & $1-2$ & 3 \\
\hline Fehér korai & $5-6$ & 5 & $6-7$ & 5 & $5-6$ & $5-6$ & 0 & 3 & 2 & 2 \\
\hline Fireball & 5 & 5 & 6 & 5 & 5 & 6 & 0 & $2-3$ & $2-3$ & 3-3 \\
\hline Flamingo & 6 & 5 & 6 & 5 & $5-6$ & $5-6$ & 0 & 2 & 2 & 2 \\
\hline Flamkist & $6-7$ & 5 & $6-7$ & $4-5$ & 6 & 6 & 0 & 2 & 2 & 2 \\
\hline Flavortop & $6-7$ & $4-5$ & 7 & 5 & 6 & 6 & 0 & 2 & 2 & 2 \\
\hline Flordaglo & 6 & 5 & 5 & 5 & $5-6$ & 6 & 0 & $1-2$ & $1-2$ & $1-2$ \\
\hline Florence & 5 & 5 & $6-7$ & 5 & 6 & 6 & 0 & $2-3$ & 2 & 2 \\
\hline Flory Dwarf & $5-6$ & 5 & 6 & $4-5$ & 5 & $5-6$ & 0 & 2 & $1-2$ & 1 \\
\hline Fodor-féle névtelen & 5 & 5 & $6-7$ & 5 & $5-6$ & 5 & $0-1$ & 2 & 1 & $1-2$ \\
\hline Ford korai & 6 & $4-5$ & 7 & $4-5$ & 5 & 6 & 0 & $1-2$ & $1-2$ & $1-2$ \\
\hline Foster & 6 & 5 & 6 & 5 & 5 & $5-6$ & 0 & 2 & 2 & 2 \\
\hline Francesco & $6-7$ & 5 & 6 & 5 & $5-6$ & 6 & 0 & $1-2$ & 2 & $1-2$ \\
\hline Frederica & $5-6$ & $4-5$ & $6-7$ & 5 & 6 & $5-6$ & 0 & 2 & 2 & 2 \\
\hline Fritzgerald & $6-7$ & 5 & 6 & 5 & $5-6$ & 6 & 0 & $2-3$ & 2 & 2 \\
\hline Frühe Mignonne & 5 & $4-5$ & 5 & 5 & $5-6$ & $5-6$ & 0 & 2 & 2 & $1-2$ \\
\hline Gain de Montreuil & $5-6$ & 5 & $5-6$ & 5 & 6 & 5 & 0 & $1-2$ & 1 & $1-2$ \\
\hline Garden Lady & 6 & 5 & $6-7$ & 5 & $5-6$ & $5-6$ & $0-1$ & 3 & 3 & 2 \\
\hline Genadix 4 & 6 & 5 & 6 & $4-5$ & $5-6$ & 5 & 0 & 2 & 2 & 2 \\
\hline General Lee & $5-6$ & $4-5$ & 5 & 5 & 5 & 5 & 0 & 2 & 2 & $2-3$ \\
\hline George IV & 5 & 5 & 5 & 5 & $5-6$ & 5 & 0 & 2 & 2 & 2 \\
\hline Georgia & $5-6$ & $4-5$ & 6 & 5 & $5-6$ & $5-6$ & 0 & 3 & 2 & 2 \\
\hline Gialla di Firenze & 6 & 5 & $6-7$ & 5 & 6 & 6 & 0 & 1 & $1-2$ & $1-2$ \\
\hline Gladys & 5 & $4-5$ & 6 & 5 & $5-6$ & 6 & 0 & 3 & $2-3$ & 2 \\
\hline Globe & 5 & $4-5$ & 6 & $4-5$ & $5-6$ & $5-6$ & 0 & 2 & 2 & $1-2$ \\
\hline Glohaven & $5-6$ & 5 & $6-7$ & 5 & 6 & 6 & 0 & 2 & 2 & 2 \\
\hline Gloria Red & $5-6$ & 5 & 6 & 5 & 6 & $5-6$ & 0 & 2 & $1-2$ & 1.2 \\
\hline Gold Drop & $5-6$ & 5 & $5-6$ & 5 & $5-6$ & $5-6$ & 0 & 1 & $1-2$ & 2 \\
\hline
\end{tabular}




\begin{tabular}{|c|c|c|c|c|c|c|c|c|c|c|}
\hline Gold Medal & 5 & 5 & 5 & 5 & $5-6$ & $5-6$ & 0 & 1 & 2 & 2 \\
\hline Golden Cling & 5 & $4-5$ & $5-6$ & $4-5$ & 5 & 6 & 0 & 2 & 2 & 2 \\
\hline Golden Eagle & 5 & $4-5$ & $5-6$ & $4-5$ & 5 & 6 & 0 & 2 & 2 & 2 \\
\hline Golden Elberta & $5-6$ & $4-5$ & 5 & 5 & 5 & $5-6$ & $0-1$ & 3 & $2-3$ & 3 \\
\hline Golden Flame & $5-6$ & 4 & 5 & 5 & 5 & 5 & 0 & $1-2$ & 2 & 2 \\
\hline Goldeneast & 5 & 5 & $5-6$ & 5 & $5-6$ & $5-6$ & 0 & 3 & 2 & 2 \\
\hline Goldhaven & 5 & 5 & 5 & 5 & $5-6$ & 4 & 0 & $1-2$ & 2 & 3 \\
\hline Goldray & $5-6$ & 5 & $5-6$ & 5 & 6 & 6 & 0 & 2 & 2 & 2 \\
\hline Gorges & 5 & 5 & 5 & $4-5$ & $5-6$ & 6 & $0-1$ & $2-3$ & $1-2$ & 2 \\
\hline Governor Hogg & 5 & $4-5$ & 5 & 5 & 5 & 6 & 0 & $2-3$ & $1-2$ & 2 \\
\hline Grand Admirable & $5-6$ & 5 & 6 & 5 & 6 & 6 & 0 & 2 & 2 & 0 \\
\hline Greensboro & $5-6$ & 5 & $5-6$ & 5 & $5-6$ & $5-6$ & 0 & $1-2$ & 2 & $2-3$ \\
\hline Groc Anis & 6 & 5 & 6 & 5 & $5-6$ & 6 & 0 & 1 & $1-2$ & $1-2$ \\
\hline Guinn & $5-6$ & $4-5$ & 5 & $4-5$ & 6 & 6 & 0 & 3 & 2 & 3 \\
\hline Gustave Thuret & 5 & $4-5$ & 5 & $4-5$ & 5 & 5 & 0 & 3 & 2 & 2 \\
\hline Gypsy & 5 & 5 & 5 & $4-5$ & 5 & 4 & 0 & $1-2$ & $1-2$ & $1-2$ \\
\hline Győztes & $5-6$ & $4-5$ & $6-7$ & 5 & $5-6$ & $5-6$ & 0 & 2 & 2 & 2 \\
\hline Gyümölcsöskertek királynője & 5 & $4-5$ & 5 & 5 & 5 & 6 & $0-1$ & $2-3$ & 2 & 2 \\
\hline Hale Early & $5-6$ & 5 & $5-6$ & 5 & $5-6$ & 6 & 0 & $3-4$ & 2 & 2 \\
\hline Halegold & 5 & 5 & $5-6$ & $4-5$ & 6 & $5-6$ & 0 & 3 & 2 & 2 \\
\hline Halehaven & 5 & 5 & $5-6$ & $4-5$ & 5 & $5-6$ & 0 & 2 & 1 & 3 \\
\hline Harbinger & 5 & 4 & 5 & $4-5$ & 5 & $5-6$ & 0 & 2 & $1-2$ & 2 \\
\hline Harko & $6-7$ & $4-5$ & 7 & 5 & 5 & 5 & $0-1$ & $1-2$ & 2 & $1-2$ \\
\hline Harris Elberta & $5-6$ & 5 & $5-6$ & 5 & $5-6$ & $5-6$ & 0 & $1-2$ & $1-2$ & 2 \\
\hline Hativê Bobo & 6-7 & 5 & $5-6$ & 5 & $5-6$ & 6 & 0 & $2-3$ & 2 & 2 \\
\hline Hawkins & 6-7 & 5 & 6 & 5 & 6 & 6 & 0 & 2 & 2 & $1-2$ \\
\hline Hayes Late & 5 & $4-5$ & 5 & 5 & $5-6$ & $5-6$ & 0 & $2-3$ & 2 & 2 \\
\hline Heath Free & $5-6$ & $4-5$ & $5-6$ & $4-5$ & 5 & $5-6$ & 0 & 2 & 2 & 2 \\
\hline Heath Cling & $5-6$ & 5 & 6 & 5 & $5-6$ & 5 & 0 & 1 & 2 & 1 \\
\hline Hegyi korai & 7 & 5 & $6-7$ & 5 & $5-6$ & $5-6$ & 0 & $2-3$ & 2 & $2-3$ \\
\hline Heidelberg & 5 & 5 & 6 & $4-5$ & 5 & 6 & 0 & 2 & 1 & 2 \\
\hline Hiland & 5 & $5-5$ & $5-6$ & 5 & 5 & $5-6$ & 0 & 2 & 2 & 2 \\
\hline Hiley & $5-6$ & 5 & 6 & 5 & $5-6$ & 6 & 0 & 2 & $1-2$ & $1-2$ \\
\hline Hoffman & 5 & 5 & 6 & $4-5$ & 5 & 5 & $0-1$ & 1 & $1-2$ & $1-2$ \\
\hline Holderbaum & 5 & $4-5$ & 5 & $4-5$ & 5 & 5 & 0 & $2-3$ & 1 & 2 \\
\hline Holt & 5 & $4-5$ & $5-6$ & 5 & $5-6$ & $5-6$ & 0 & $2-3$ & 2 & 2 \\
\hline Honey & 5 & $4-5$ & 5 & $4-5$ & $5-6$ & $5-6$ & 0 & 2 & 2 & 2 \\
\hline Honey Dew Hale & $5-6$ & $4-5$ & $5-6$ & $4-5$ & 6 & $5-6$ & 0 & 1 & $1-2$ & $1-2$ \\
\hline Honey Nectarine & 5 & 5 & 5 & 5 & $5-6$ & $5-6$ & 0 & 2 & 2 & 2 \\
\hline Honey Peach & $5-6$ & 5 & $6-7$ & 5 & $5-6$ & 6 & 0 & 2 & $2-3$ & 2 \\
\hline Honeyberta & $5-6$ & 4 & 5 & $4-5$ & $5-6$ & 5 & 0 & 2 & 2 & 2 \\
\hline Howard & 5 & $4-5$ & $5-6$ & 5 & 5 & $5-6$ & 0 & $1-2$ & $1-2$ & $1-2$ \\
\hline Howard Fisher & $5-6$ & $4-5$ & 5 & 5 & $5-6$ & 5 & $0-1$ & $1-2$ & 2 & 2 \\
\hline Hynes & 6 & $4-5$ & 5 & 5 & 6 & $5-6$ & 0 & 2 & $1-2$ & 2 \\
\hline Ideal & 5 & $4-5$ & 6 & $4-5$ & $5-6$ & $5-6$ & 0 & 2 & 2 & 2 \\
\hline Illinois & $6-7$ & 5 & $5-6$ & 5 & 5 & 5 & $0-1$ & 1 & $1-2$ & $1-2$ \\
\hline Imperial & 5 & $4-5$ & 5 & $4-5$ & $5-6$ & $5-6$ & 0 & 2 & 2 & 2 \\
\hline Improved Elberta & $5-6$ & 5 & 5 & 6 & 6 & 6 & 0 & 2 & 2 & $1-2$ \\
\hline Incrocio Pieri & 6 & 5 & $6-7$ & 5 & $5-6$ & $5-6$ & 0 & $2-3$ & 2 & 2 \\
\hline Independence & 7 & 5 & 6 & 6 & 6 & 6 & 0 & $1-2$ & 3 & 3 \\
\hline Indian Free & 5 & 4 & $6-7$ & 5 & 5 & $5-6$ & 0 & 2 & $2-3$ & $2-3$ \\
\hline Infanta Isabel & 6 & $4-5$ & 6 & 5 & 6 & 6 & 0 & $2-3$ & 2 & 2 \\
\hline Iron Mountain & 5 & 5 & 5 & 5 & 6 & 5 & 0 & 3 & 2 & 2 \\
\hline Isaure Kelemen & $5-6$ & $4-5$ & 6 & 4 & 5 & $5-6$ & 0 & $3-4$ & $1-2$ & 2 \\
\hline J. H. Hale & $6-7$ & $4-5$ & $6-7$ & 5 & 5 & $5-6$ & $0-1$ & $1-2$ & 2 & $1-2$ \\
\hline J. L. Ames & $6-7$ & 5 & 6 & $4-5$ & 6 & 6 & 0 & 2 & $1-2$ & 2 \\
\hline Jacques & $5-6$ & 5 & $5-6$ & 5 & $5-6$ & 5 & 0 & $2-3$ & $1-2$ & $1-2$ \\
\hline Japanese Dwarf & 6 & 5 & $6-7$ & $4-5$ & 6 & $5-6$ & 0 & 2 & $2-3$ & 2 \\
\hline Jeanne Chatain & $5-6$ & 4 & 5 & 4 & $5-6$ & 5 & 0 & 1 & $1-2$ & 1 \\
\hline Jennie Worthen & $5-6$ & 5 & $5-6$ & 5 & $5-6$ & 5 & 0 & $1-2$ & 2 & 2 \\
\hline
\end{tabular}




\begin{tabular}{|c|c|c|c|c|c|c|c|c|c|c|}
\hline Jerseyland & $6-7$ & $4-5$ & $6-7$ & 5 & 5 & $5-6$ & $0-1$ & 1 & 2 & 2 \\
\hline Jewel & 6 & 5 & $5-6$ & 5 & 5 & 6 & 0 & $1-2$ & $2-3$ & $2-3$ \\
\hline Jubilant & $5-6$ & $4-5$ & $5-6$ & 5 & 5 & 6 & 0 & $1-2$ & 2 & 2 \\
\hline Jubilejnij & $5-6$ & $4-5$ & 5 & 5 & $5-6$ & 5 & 0 & $1-2$ & 2 & $1-2$ \\
\hline Julian & $6-7$ & $4-5$ & $6-7$ & $4-5$ & 5 & 5 & 0 & $1-2$ & $1-2$ & $1-2$ \\
\hline July Elberta & 6 & 5 & $5-6$ & 5 & $5-6$ & $5-6$ & 0 & 3 & 2 & $2-3$ \\
\hline July Hale & $5-6$ & $4-5$ & 5 & 5 & 5 & $5-6$ & $0-1$ & 2 & 2 & 2 \\
\hline July Heath & 6 & 4 & 5 & $4-5$ & 6 & $5-6$ & 0 & 2 & 2 & 2 \\
\hline July Lady & 6 & $4-5$ & $5-6$ & 5 & 5 & 6 & 0 & 2 & 2 & $2-3$ \\
\hline July Queen & $5-6$ & 5 & $5-6$ & $4-5$ & $5-6$ & $5-6$ & 0 & $2-3$ & $2-3$ & 2 \\
\hline Jun-berta & 6 & 5 & $6-7$ & $4-5$ & 6 & $5-6$ & 0 & $2-3$ & 2 & $2-3$ \\
\hline Junegold & 5 & $4-5$ & 6 & 5 & $5-6$ & 3 & 0 & $2-3$ & 2 & 2 \\
\hline Jungermanm & 5 & $4-5$ & 6 & $4-5$ & 5 & $5-6$ & 0 & $1-2$ & $1-2$ & $1-2$ \\
\hline Kalamazoo & 6 & 5 & 6 & 5 & 6 & 5 & $0-1$ & 1 & $1-2$ & $1-2$ \\
\hline Kamdesa & $6-7$ & 5 & $5-6$ & 5 & $5-6$ & 6 & 0 & $2-3$ & $2-3$ & 2 \\
\hline Karmen Rozova & 6 & 5 & $5-6$ & $4-5$ & 6 & $5-6$ & $0-1$ & 2 & 2 & $2-3$ \\
\hline Kathryn & $5-6$ & $4-5$ & 6 & $4-5$ & $5-6$ & 6 & 0 & 2 & 2 & 2 \\
\hline Kecskeméti duránci & $5-6$ & $4-5$ & $5-6$ & $4-5$ & 5 & $5-6$ & 0 & 1 & $1-2$ & 1 \\
\hline Keimess & 5 & $4-5$ & 5 & 4 & $5-6$ & $5-6$ & 0 & 2 & 2 & 2 \\
\hline Kelvin Cling & $5-6$ & 5 & $5-6$ & 5 & 6 & $5-6$ & 0 & 2 & 2 & $2-3$ \\
\hline Kentucky & 5 & 5 & 5 & $4-5$ & $5-6$ & $5-6$ & 0 & $1-2$ & 2 & 2 \\
\hline Kései bronzos Elberta & 6 & 5 & 6 & 5 & $5-6$ & 5 & $0-1$ & $2-3$ & $1-2$ & 2 \\
\hline Kestrel & 5 & $4-5$ & 5 & 5 & 5 & $5-6$ & 0 & 2 & 2 & $1-2$ \\
\hline Kette & $5-6$ & $4-5$ & $5-6$ & $4-5$ & $5-6$ & 6 & 0 & 2 & $2-3$ & 2 \\
\hline Keystone & $5-6$ & 4 & $5-5$ & $4-5$ & 6 & $5-6$ & 0 & $2-3$ & 2 & 2 \\
\hline Kia Ora & 6 & 5 & 5 & 5 & 6 & 6 & 0 & 2 & 2 & $2-3$ \\
\hline Kievski pozdnij & 6 & $4-5$ & $5-6$ & $4-5$ & 5 & 5 & 0 & 2 & 1 & 1 \\
\hline Kievski rannijj & 6 & 5 & $5-6$ & 4 & 5 & 5 & $0-1$ & $1-2$ & 2 & 1 \\
\hline Kievskij & $5-6$ & $4-5$ & 5 & 4 & 5 & 5 & 0 & 2 & 1 & 1 \\
\hline Kim Earling & $5-6$ & 5 & $6-7$ & $4-5$ & 6 & $5-6$ & 0 & $2-3$ & 2 & 2 \\
\hline Kimbo & $5-6$ & 5 & $6-7$ & 5 & $5-6$ & 6 & 0 & 2 & 2 & $2-3$ \\
\hline Kirkman Gem & $5-6$ & $4-5$ & 6 & $4-5$ & 65 & $5-6$ & 0 & $2-3$ & 2 & 2 \\
\hline Klamt & $6-7$ & $4-5$ & $6-7$ & 5 & 5 & 5 & 0 & 2 & $1-2$ & $1-2$ \\
\hline Kraprim & 7 & 5 & 6 & 5 & $5-6$ & 5 & 0 & 2 & 2 & 1 \\
\hline Krasnovostočnij & $5-6$ & 4 & 5 & 4 & 5 & 5 & 0 & $1-2$ & 2 & 2 \\
\hline Kremlevskij & $5-6$ & 4 & $5-6$ & 4 & 5 & $5-6$ & 0 & 2 & 2 & 2 \\
\hline Krupna Badenska & $5-6$ & 5 & 6 & 5 & 6 & $5-6$ & 0 & 2 & $2-3$ & 2 \\
\hline Krümcsanyin & $5-6$ & $4-5$ & $5-6$ & $4-5$ & 5 & 5 & 0 & $1-2$ & $1-2$ & 2 \\
\hline Kyrmyzy-Jarma & 5 & 5 & 5 & 4 & 6 & 5 & $0-1$ & 2 & 2 & $1-2$ \\
\hline La Gem & $6-7$ & 5 & 6 & 5 & $5-6$ & 6 & 0 & 2 & $2-3$ & 2 \\
\hline La Premiere & 7 & 5 & 5 & 5 & $5-6$ & $5-6$ & 0 & $1-2$ & $2-3$ & 2 \\
\hline Laczy-féle duránci & 6 & $4-5$ & 6 & $4-5$ & 5 & 5 & 0 & 2 & $1-2$ & $1-2$ \\
\hline Lady Palmerston & $6-7$ & 5 & 6 & $4-5$ & 5 & $5-6$ & 0 & 2 & 2 & 2 \\
\hline Lambertin No. 1 & $5-6$ & $4-5$ & $5-6$ & $4-5$ & 6 & 5 & 0 & 1 & $1-2$ & 1 \\
\hline Lamont & 5 & $4-5$ & 5 & $4-5$ & $5-6$ & 5 & 0 & 2 & $1-2$ & 2 \\
\hline Late Alamar & 6 & 5 & 6 & $4-5$ & 6 & 5 & 0 & $1-2$ & 2 & 2 \\
\hline Late Crawford & 5 & $4-5$ & $5-6$ & 5 & $5-6$ & $5-6$ & 0 & 3 & $2-3$ & 2 \\
\hline Late Elberta & $5-6$ & $4-5$ & $6-7$ & 4 & 5 & $5-6$ & $0-1$ & 2 & $2-3$ & $1-2$ \\
\hline Late J. H. Hale & 6 & 5 & 5 & 5 & 6 & 5 & 0 & 2 & 2 & 2 \\
\hline Late Kirkman & $5-6$ & 5 & $5-6$ & $4-5$ & $5-6$ & 6 & 0 & $2-3$ & 2 & 2 \\
\hline Late Rarekile & 5 & $4-5$ & 5 & 5 & 6 & 5 & 0 & 2 & 2 & 2 \\
\hline Late Rio Oso & 6 & 5 & 7 & 5 & $6-7$ & 6 & 0 & 2 & $1-2$ & $1-2$ \\
\hline Late Rose & 6 & $4-5$ & $5-6$ & $4-5$ & $5-6$ & $5-6$ & 0 & 2 & $1-2$ & 2 \\
\hline Late Yellow Alberge & 5 & $4-5$ & $5-6$ & 5 & $5-6$ & 6 & 0 & 2 & $2-3$ & 2 \\
\hline Latvian & 5 & 5 & 6 & 4 & $5-6$ & 5 & $0-1$ & $1-2$ & $1-2$ & $1-2$ \\
\hline Leeton & 5 & $4-5$ & $5-6$ & 5 & 5 & $5-6$ & 0 & $1-2$ & $1-2$ & 2 \\
\hline Le Grand & $5-6$ & $4-5$ & 5 & $4-5$ & $5-6$ & 7 & $0-1$ & 2 & 2 & 2 \\
\hline Lemon Cling & 6 & 5 & $6-7$ & 5 & $5-6$ & 6 & 0 & $2-3$ & 2 & 2 \\
\hline Lemon Dolorosa & 6 & 5 & 6 & 5 & $5-6$ & 6 & 0 & $2-3$ & 2 & $2-3$ \\
\hline Lemon Free & $6-7$ & 5 & 6 & 5 & 6 & 6 & 0 & $2-3$ & 2 & 2 \\
\hline
\end{tabular}




\begin{tabular}{|c|c|c|c|c|c|c|c|c|c|c|}
\hline Lena & $5-6$ & 5 & 5 & $4-5$ & 5 & $5-6$ & 0 & $1-2$ & $1-2$ & 2 \\
\hline Levis Cling & 6 & $4-5$ & $5-6$ & $4-5$ & 5 & 5 & 0 & 2 & 2 & $1-2$ \\
\hline Lewy & $5-6$ & $4-5$ & 6 & 5 & $5-6$ & $5-6$ & 0 & 2 & 2 & 2 \\
\hline Lexington & 5 & 5 & 5 & 4 & 5 & 5 & 0 & 2 & $1-2$ & 2 \\
\hline Licking & 5 & 5 & $5-6$ & $4-5$ & 6 & $5-6$ & 0 & 2 & $1-2$ & 1 \\
\hline Linden & $5-6$ & $4-5$ & 5 & 5 & 6 & 5 & 0 & $1-2$ & 1 & $1-2$ \\
\hline Linworth & 5 & 5 & 5 & 4 & 6 & 6 & $0-1$ & $1-2$ & 2 & 2 \\
\hline Lippiat & 5 & 5 & $5-6$ & $4-5$ & 5 & $5-6$ & 0 & 2 & 1 & 2 \\
\hline Lisbeth & 5 & $4-5$ & 6 & 5 & $5-6$ & $5-6$ & 0 & 2 & $2-3$ & $2-3$ \\
\hline Lizzie & 6 & 5 & $5-6$ & $4-5$ & 5 & $5-6$ & 0 & $1-2$ & 2 & $1-2$ \\
\hline Loadel & 6 & $4-5$ & $6-7$ & $4-5$ & 5 & 5 & 0 & 2 & 2 & 2 \\
\hline Lodge & $5-6$ & 5 & $5-6$ & 4 & 6 & $5-6$ & $0-1$ & $2-3$ & 2 & $2-3$ \\
\hline Lola & 6 & $4-5$ & 6 & 5 & $5-6$ & $5-6$ & 0 & $2-3$ & 2 & $2-3$ \\
\hline Londyke Early Elberta & $6-7$ & 5 & $6-7$ & $4-5$ & 6 & 6 & 0 & 2 & 2 & 2 \\
\hline Lord Napier & 6 & 5 & $5-6$ & 5 & $5-6$ & $5-6$ & 0 & $1-2$ & $1-2$ & $1-2$ \\
\hline Lord Palmerston & $6-7$ & 5 & 6 & $4-5$ & 5 & $5-6$ & 0 & 2 & $1-2$ & $1-2$ \\
\hline Loring & 6 & $4-5$ & 6 & 5 & $5-6$ & 5 & 0 & 2 & 2 & 2 \\
\hline Lovell & 5 & 5 & $5-6$ & 5 & 5 & 5 & 0 & 2 & $1-2$ & $1-2$ \\
\hline Lovettl & 6 & $4-5$ & 7 & $4-5$ & 5 & 5 & 0 & 3 & 2 & $1-2$ \\
\hline Lucas & 6 & $4-5$ & $5-6$ & $4-5$ & $5-6$ & $5-6$ & 0 & 2 & 2 & $2-3$ \\
\hline Luckens & $5-6$ & $4-5$ & 6 & 5 & 5 & 6 & 0 & $1-2$ & $1-2$ & 2 \\
\hline Lulu & 5 & 5 & 5 & $4-5$ & 6 & $5-6$ & 0 & $2-3$ & 2 & $2-3$ \\
\hline Luna & $6-7$ & 5 & 6 & 5 & $5-6$ & 5 & 0 & 2 & 2 & 2 \\
\hline Mabel & 7 & 5 & $6-7$ & 5 & 6 & 6 & 0 & 3 & 2 & 2 \\
\hline Madame Bay & 5 & $4-5$ & 5 & 4 & 6 & 5 & 0 & 2 & $1-2$ & 2 \\
\hline Madame Pouyett & $6-7$ & 5 & 6 & 5 & $5-6$ & $5-6$ & 0 & 2 & 2 & 2 \\
\hline Madame Venet & 6 & 5 & 6 & 4 & 5 & $5-6$ & 0 & 3 & $2-3$ & 2 \\
\hline Madeleine Payuenne & 6 & $4-5$ & $5-6$ & 5 & 6 & 6 & 00 & 2 & 2 & 1 \\
\hline Madeleine Pouyet & $6-7$ & $4-5$ & $6-7$ & 5 & 5 & 5 & 0 & 3 & $2-3$ & 2 \\
\hline Maffey & $5-6$ & 5 & $5-5$ & $4-5$ & $5-6$ & $5-6$ & 0 & $2-3$ & 2 & $2-3$ \\
\hline Maglia Rosa & $5-6$ & 5 & 6 & $4-5$ & 5 & 6 & 0 & $1-2$ & $1-2$ & $1-2$ \\
\hline Magyar aranyduráncija & 5 & 4 & 5 & $4-5$ & $5-6$ & 5 & $0-1$ & $1-2$ & $1-2$ & 2 \\
\hline Maluti & 6 & 5 & $5-6$ & 5 & 6 & 6 & 0 & 1 & 2 & $1-2$ \\
\hline Mamie Ross & $5-6$ & $4-5$ & 6 & 4 & 5 & $5-6$ & 0 & 2 & 2 & 2 \\
\hline Manon & 5 & $4-5$ & 6 & 5 & 6 & 6 & 0 & $2-3$ & 2 & $1-2$ \\
\hline Maria Bianca & $5-6$ & 4 & $6-7$ & 5 & $5-6$ & 5 & 0 & $2-3$ & 2 & 2 \\
\hline Maria Carla & 5 & 5 & $5-6$ & $4-5$ & 6 & $5-6$ & 0 & 2 & $1-2$ & $1-2$ \\
\hline Maria Delizia & 6 & $4-5$ & $5-6$ & 5 & 6 & $5-6$ & 0 & 2 & $1-2$ & 2 \\
\hline Marigold & 6 & 5 & 6 & 5 & $5-6$ & 5 & $0-1$ & 2 & $1-2$ & $1-2$ \\
\hline Marilyn & $5-6$ & 5 & 6 & $4-5$ & $5-6$ & $5-6$ & 0 & $1-2$ & 2 & 2 \\
\hline Mariska & 6 & 4 & 7 & 4 & 5 & $5-6$ & 0 & $1-2$ & 2 & 3 \\
\hline Marquette & $6-7$ & 5 & $5-6$ & 5 & $5-6$ & 6 & 0 & 2 & $1-2$ & 2 \\
\hline Maxime & 6 & 5 & 6 & 5 & 5 & $5-6$ & 0 & $2-3$ & 2 & 2 \\
\hline Maybelle & $6-7$ & 5 & $5-6$ & 5 & 5 & 5 & 0 & 3 & 2 & $1-2$ \\
\hline Maycrest & 5 & $4-5$ & $6-7$ & 5 & $5-6$ & 5 & 0 & 2 & 2 & 2 \\
\hline Mayfair & 6 & $4-5$ & $5-6$ & $4-5$ & 5 & $5-6$ & 0 & 2 & $1-2$ & 2 \\
\hline Mayflower & $5-6$ & $4-5$ & $6-7$ & $4-5$ & $5-6$ & $5-6$ & 0 & 2 & 2 & 2 \\
\hline Maygold & 5 & 5 & 6 & 5 & 6 & $5-6$ & 0 & $1-2$ & $1-2$ & 2 \\
\hline Maystar & 7 & $4-5$ & 6 & 4 & $5-6$ & 6 & 0 & $2-3$ & 2 & $1-2$ \\
\hline Maytime & 6 & 4 & $5-6$ & 5 & 6 & 6 & $0-1$ & 3 & $2-3$ & 2 \\
\hline Maywel & $6-7$ & 5 & 6 & 5 & $5-6$ & $5-6$ & 0 & 2 & 2 & 2 \\
\hline McAllister & 5 & $4-5$ & $5-6$ & 5 & 6 & 5 & 0 & $2-3$ & 2 & $2-3$ \\
\hline McCune & $5-6$ & 5 & 6 & 5 & $5-6$ & 5 & 0 & 2 & 2 & 2 \\
\hline McKay & 6 & $4-5$ & 5 & $4-5$ & 5 & $5-6$ & 0 & $1-2$ & 2 & 1 \\
\hline McKune & $5-6$ & 5 & 5 & 5 & 6 & $5-6$ & 0 & 3 & $2-3$ & $2-3$ \\
\hline Meadow & 5 & $4-5$ & 4 & $4-5$ & $5-6$ & 5 & 0 & 2 & 2 & 2 \\
\hline Medovij & 5 & 5 & 5 & $4-5$ & 5 & 5 & 0 & 2 & 2 & $1-2$ \\
\hline Meigue Panteo & $5-6$ & $4-5$ & 6 & $4-5$ & $5-6$ & $6-7$ & 0 & 3 & 1 & $2-3$ \\
\hline Melba & 6 & 5 & $5-6$ & 5 & 6 & 6 & $0-1$ & 2 & 2 & 2 \\
\hline Melvin & 5 & 5 & 5 & 4 & $5-6$ & $5-6$ & 0 & $2-3$ & 2 & $1-2$ \\
\hline
\end{tabular}




\begin{tabular}{|c|c|c|c|c|c|c|c|c|c|c|}
\hline Merill Gem & $5-6$ & 5 & 4 & $4-5$ & 5 & $6-7$ & 0 & 3 & $2-3$ & 2 \\
\hline Merrill Schooldays & $5-6$ & $4-5$ & 5 & 5 & 5 & 5 & 0 & 2 & 2 & 2 \\
\hline Merry Gold & 6 & $4-5$ & 5 & $4-5$ & 5 & 6 & $0-1$ & $1-2$ & 2 & $1-2$ \\
\hline Metelka díjazottja & 6 & 4 & 6 & $4-5$ & $5-6$ & 5 & 0 & $1-2$ & $1-2$ & $1-2$ \\
\hline Meteor & 5 & 5 & $5-6$ & 5 & $5-6$ & $5-6$ & 0 & 2 & 2 & 2 \\
\hline Mezőkomáromi duránci & 6-7 & 4 & 6 & $4-5$ & 5 & 5 & 0 & 2 & $1-2$ & 1 \\
\hline Michelini & 7 & 5 & 6 & 5 & $5-6$ & 6 & 0 & $1-2$ & 2 & 2 \\
\hline Michelson & $5-6$ & 5 & 5 & $4-5$ & $5-6$ & $5-6$ & 0 & 2 & $1-2$ & $1-2$ \\
\hline Michigan Late & 5 & 4 & 4 & $4-5$ & 5 & $5-6$ & 0 & 2 & 1 & 1 \\
\hline Michigold & $5-6$ & 5 & $5-6$ & 4 & 6 & 5 & 0 & $1-2$ & 2 & 3 \\
\hline Midway & 5 & 4 & $5-6$ & $4-5$ & 5 & 6 & $0-1$ & 1 & $1-2$ & $1-2$ \\
\hline Miiss Lolo & $6-7$ & $4-5$ & 6 & 5 & $5-6$ & $5-6$ & 0 & $2-3$ & 2 & 2 \\
\hline Millhiser & 5 & $4-5$ & 6 & 5 & 5-6 & 6 & 0 & 2 & $1-2$ & 3 \\
\hline Minjon & 5 & 5 & $5-6$ & 5 & 6 & $5-6$ & 0 & 3 & 2 & 2 \\
\hline Moore Favourite & 5 & $4-5$ & $5-6$ & $4-5$ & 5 & 6 & 0 & 2 & $1-2$ & $1-2$ \\
\hline Morettini 1 & 6 & 5 & 6 & $4-5$ & $5-6$ & $6-7$ & 0 & $1-2$ & 2 & $1-2$ \\
\hline Morris White & $5-6$ & 5 & $5-6$ & 5 & $5-6$ & $5-6$ & 0 & $1-2$ & $1-2$ & $1-2$ \\
\hline Morton & 6 & 5 & $5-6$ & 5 & 6 & $5-6$ & 0 & $1-2$ & 2 & 2 \\
\hline Mountain Rose & $6-7$ & 5 & 6 & $4-5$ & 5 & 6 & $0-1$ & $1-2$ & $1-2$ & $1-2$ \\
\hline Muir & 6 & 5 & $5-6$ & 4 & 6 & $5-6$ & 0 & 2 & 2 & 2 \\
\hline Muza & 5 & $4-5$ & 5 & $4-5$ & 5 & $5-6$ & $0-1$ & 2 & $2-3$ & 2 \\
\hline Nagy Mignon & $6-7$ & 4 & 6 & 5 & 5 & 6 & 0 & 3 & 2 & 2 \\
\hline Narindzij & 5 & 4 & $5-6$ & 5 & $5-6$ & 5 & 0 & $1-2$ & $1-2$ & $1-2$ \\
\hline Nectacrest & 6 & 5 & 6 & 5 & 6 & 6 & 0 & 2 & 2 & 2 \\
\hline Nectalate & $5-6$ & 5 & $5-6$ & 5 & 6 & 6 & 0 & 2 & 1 & $1-2$ \\
\hline Nectared 2 & 6 & 5 & 6 & $4-5$ & 6 & $5-6$ & 0 & 3 & 2 & $2-3$ \\
\hline Nectared 3 & 6 & 5 & 6 & 5 & 6 & $5-6$ & 0 & $2-3$ & 2 & 2 \\
\hline Nectared 4 & $6-7$ & 5 & 7 & $4-5$ & $5-6$ & 6 & 0 & 2 & 1 & $1-2$ \\
\hline Nectared 5 & $6-7$ & $4-5$ & 7 & 5 & 6 & 5 & 0 & $2-3$ & 1 & 2 \\
\hline Nectared 6 & $6-7$ & 5 & $6-7$ & $4-5$ & 5 & $5-6$ & 0 & 2 & $2-2$ & 2 \\
\hline Nectared 7 & 6 & $4-5$ & $6-7$ & 5 & 6 & 6 & 0 & $2-3$ & $2-3$ & 2 \\
\hline Nectared 8 & $6-7$ & 5 & $6-7$ & $4-5$ & 5 & $5-6$ & 0 & 2 & 2 & $1-2$ \\
\hline Nectared 9 & $6-7$ & 5 & 6 & 5 & 6 & 6 & 0 & 3 & 2 & 2 \\
\hline Nectared 10 & 6 & 5 & 6 & 5 & $5-6$ & $5-6$ & 0 & 4 & $2-3$ & $2-3$ \\
\hline Nectarine Early Flame & 6 & 5 & 6 & $4-5$ & 5 & $5-6$ & 0 & 2 & 2 & 2 \\
\hline Nectarine Philip & 6 & $4-5$ & $5-6$ & 5 & $5-6$ & 5 & 0 & 1 & 2 & 2 \\
\hline Nectaross & $6-7$ & 5 & 6 & 5 & 6 & $5-6$ & 0 & $1-2$ & $1-2$ & $1-2$ \\
\hline Nektár H. & 6 & 5 & $6-7$ & $4-5$ & 5 & 6 & 0 & $1-2$ & 1 & $1-2$ \\
\hline Nemagourd & $5-6$ & $4-5$ & 6 & 5 & 5 & 5 & 0 & 2 & 2 & $1-2$ \\
\hline Nestor & 5 & $4-5$ & $5-6$ & 5 & 6 & $5-6$ & $0-1$ & $1-2$ & $1-2$ & 2 \\
\hline New Boy & 5 & 5 & $5-6$ & 5 & $5-6$ & 5 & 0 & 2 & 2 & 2 \\
\hline New White & 6 & 5 & 6 & 5 & 5 & 5 & 0 & $1-2$ & $1-2$ & $2-3$ \\
\hline Newton & $5-6$ & $4-5$ & $5-6$ & 5 & 6 & 6 & 0 & 2 & 2 & 2 \\
\hline Niagara & 5 & 5 & $5-6$ & $4-5$ & $5-6$ & 5 & 0 & 2 & 2 & $1-2$ \\
\hline Nivette & $5-6$ & $4-5$ & $5-6$ & 5 & 6 & 5 & 0 & $2-3$ & 2 & $2-3$ \\
\hline Nonpareil & 5 & 5 & 5 & $4-5$ & 5 & 5 & 0 & $1-2$ & $1-2$ & $1-2$ \\
\hline Norwalk Free & 5 & $4-5$ & 5 & $4-5$ & $5-6$ & 5 & 0 & 2 & 2 & 2 \\
\hline Novelred & $5-6$ & 5 & 6 & $4-5$ & 5 & $5-6$ & 0 & $2-3$ & 2 & 2 \\
\hline Nyikitai laposbarack & 6 & 5 & 5 & 5 & $5-6$ & 6 & 0 & 2 & 2 & 1 \\
\hline O’Henry & 5 & $4-5$ & $5-6$ & 4 & 5 & 5 & 0 & 2 & 2 & 2 \\
\hline Obil'nij & 5 & $4-5$ & 5 & 4 & 5 & 5 & $0-1$ & $1-2$ & $1-2$ & 2 \\
\hline Oclaberta & $5-6$ & 5 & $5-6$ & 5 & 6 & $5-6$ & 0 & 2 & 2 & 2 \\
\hline October Elberta & $5-6$ & 5 & $5-6$ & 5 & 6 & $5-6$ & 0 & 3 & 2 & 2 \\
\hline Okinawa & $6-7$ & 5 & $6-7$ & $4-5$ & 5 & $5-6$ & 0 & $2-3$ & $2-3$ & $2-3$ \\
\hline Oldmixon Cling & $5-6$ & $4-5$ & 5 & 5 & $5-6$ & 5 & 0 & $1-2$ & 2 & $1-2$ \\
\hline Oldmixon Free & 6 & 5 & $5-6$ & $4-5$ & $5-6$ & $5-6$ & 0 & 2 & 2 & 2 \\
\hline Olga királynő & $5-6$ & 5 & 6 & 5 & $5-6$ & 6 & 0 & 3 & $2-3$ & 2 \\
\hline Olinda & 5 & 5 & $5-6$ & 5 & 6 & 6 & 0 & 2 & 2 & 2 \\
\hline Ontario & 5 & $4-5$ & $5-6$ & $4-5$ & 6 & $5-6$ & 0 & $1-2$ & $1-2$ & $1-2$ \\
\hline Orange Cling & 6 & 5 & 6 & 5 & $5-6$ & 5 & 0 & 2 & 2 & $2-3$ \\
\hline
\end{tabular}




\begin{tabular}{|c|c|c|c|c|c|c|c|c|c|c|}
\hline Orchard Queen & 5 & 5 & $5-6$ & 5 & $5-6$ & $5-6$ & $0-1$ & 1 & $1-2$ & $1-2$ \\
\hline Óriási duránci & 5 & 5 & 5 & 5 & 5 & 5 & 0 & $2-3$ & $2-3$ & 2 \\
\hline Oriole & 5 & $4-5$ & $5-6$ & $4-5$ & 5 & 5 & 0 & 2 & 2 & $2-3$ \\
\hline Othello & 6 & 5 & 6 & 5 & 6 & $5-6$ & $0-1$ & $2-3$ & 2 & $2-3$ \\
\hline Ozark & $6-7$ & 5 & 6 & 5 & 6 & 6 & 0 & 2 & $2-3$ & 3 \\
\hline Paczelt magonca & 5 & 4 & 5 & $4-5$ & $5-6$ & 6 & 0 & $1-2$ & 2 & 2 \\
\hline Padana & $5-6$ & $4-5$ & 5 & 5 & 5 & 6 & 0 & 2 & 2 & 2 \\
\hline Palazzina & $6-7$ & 5 & 6 & 5 & 6 & 6 & 0 & $2-3$ & $2-3$ & $2-3$ \\
\hline Pallas & $5-6$ & 5 & 5 & 5 & 5 & $5-6$ & $0-1$ & 2 & $1-2$ & 2 \\
\hline Palomar & 5 & $4-5$ & $5-6$ & 5 & $5-6$ & 5 & 0 & $1-2$ & 2 & $1-2$ \\
\hline Paloro & $6-7$ & 5 & $5-6$ & $4-5$ & $5-6$ & 5 & 0 & $1-2$ & 2 & $1-2$ \\
\hline Paragon & $5-6$ & $4-5$ & 5 & 4 & 5 & $5-6$ & 0 & 2 & 2 & 2 \\
\hline Paramint & $5-6$ & 5 & 5 & 5 & 6 & 6 & 0 & 2 & 2 & $1-2$ \\
\hline Parasise & $6-7$ & 5 & 6 & $4-5$ & $5-6$ & $5-6$ & 0 & 2 & 2 & 2 \\
\hline Pauni & 5 & 4 & 5 & 4 & 5 & $5-6$ & 0 & $1-2$ & 2 & 2 \\
\hline Pavie Coronado & 6 & 5 & 6 & 5 & $5-6$ & $5-6$ & 0 & 2 & 2 & $1-2$ \\
\hline Pavie Cortez & 5 & 5 & $5-6$ & 5 & $5-6$ & $5-6$ & 0 & 2 & 2 & 2 \\
\hline Pavie de Pamiers & $5-6$ & $4-5$ & 6 & $4-5$ & 5 & 6 & 0 & 2 & 2 & 2 \\
\hline Pavie de Pompone & $5-6$ & $4-5$ & $5-6$ & $4-5$ & $5-6$ & 6 & 0 & 2 & 1 & $2-3$ \\
\hline Pavie Fontana & 6 & 5 & $5-6$ & 5 & $5-6$ & $5-6$ & 0 & 1 & 2 & 2 \\
\hline Pavie Tuscan & 5 & $4-5$ & 6 & $4-5$ & 6 & 6 & 0 & $2-3$ & 2 & 3 \\
\hline Pavie Vivian & 6 & 5 & $5-6$ & 5 & $5-6$ & $5-6$ & 0 & $2-3$ & 2 & 2 \\
\hline Peak & 5 & 4 & 5 & $4-5$ & 5 & 5 & $0-1$ & 1 & $1-2$ & $1-2$ \\
\hline Pearson & 6 & 5 & $5-6$ & $4-5$ & 5 & $5-6$ & 0 & $2-3$ & 2 & $1-2$ \\
\hline Pederson & 5 & 4 & $5-6$ & $4-5$ & $5-6$ & $5-6$ & 0 & $1-2$ & 2 & 1 \\
\hline Peento & 6 & 5 & 6 & 5 & 6 & 6 & 0 & 3 & 2 & 3 \\
\hline Pegaso & 5 & $4-5$ & 5 & $4-5$ & 5 & 5 & 0 & 2 & $1-2$ & 2 \\
\hline Penelope & 6 & 5 & 5 & 5 & 6 & 6 & 0 & $2-3$ & 2 & 2 \\
\hline Perfect Hale & $5-6$ & 5 & 6 & 5 & 6 & 6 & 0 & $1-2$ & $1-2$ & $1-2$ \\
\hline Perkins & 6 & 4 & 5 & 5 & $5-6$ & $5-6$ & $0-1$ & 2 & 2 & 2 \\
\hline Perla & 6 & 5 & 5 & 5 & 6 & 6 & 0 & 2 & 2 & $2-3$ \\
\hline Persique & 6 & 5 & 6 & 5 & 6 & $5-6$ & 0 & $1-2$ & 2 & 2 \\
\hline Pervaja & 5 & 4 & 5 & 5 & 5 & 5 & 0 & $1-2$ & 1 & $1-2$ \\
\hline Petite Mignone & $6-7$ & 5 & 6 & 5 & 6 & $5-6$ & 0 & 2 & $2-3$ & 2 \\
\hline Picquet Late & $5-6$ & 5 & 6 & $4-5$ & 5 & $5-6$ & 0 & 2 & 2 & 2 \\
\hline Piros Magdolna & 6 & $4-5$ & $5-6$ & 5 & $5-6$ & 6 & 0 & $2-3$ & 2 & 2 \\
\hline Piroska & 6 & 4 & 6 & 4 & 5 & $5-6$ & $0-1$ & 1 & $1-2$ & $1-2$ \\
\hline Plant & $5-6$ & $4-5$ & 5 & $4-5$ & $5-6$ & 5 & 0 & 3 & 2 & 2 \\
\hline Pocahantos & $6-7$ & 5 & $6-7$ & 5 & $5-6$ & 5 & 0 & $2-3$ & $2-3$ & 2 \\
\hline Poenta & 6 & 4 & 5 & $4-5$ & $5-6$ & $5-6$ & 0 & 2 & 2 & 2 \\
\hline Polessk & 5 & 5 & 6 & 4 & 5 & 5 & $0-1$ & 2 & $1-2$ & 2 \\
\hline Polnij & 5 & 4 & 5 & 4 & 5 & 5 & 0 & $1-2$ & 1 & 1 \\
\hline Poppy & $5-6$ & 5 & 6 & 5 & 5 & 6 & 0 & $2-3$ & 2 & 2 \\
\hline Posrednik & 5 & $4-5$ & $5-6$ & $4-5$ & 5 & 5 & $0-1$ & $1-2$ & 2 & 2 \\
\hline Pourple de Saint-Genis-Laval & 6 & 5 & 6-7 & 5 & $5-6$ & $5-6$ & 0 & 2 & 2 & 1 \\
\hline Prairie Dawon & 5 & $4-5$ & $5-6$ & 5 & 6 & 6 & 0 & 2 & 2 & 2 \\
\hline Prenda & $5-8$ & 4 & 6 & 5 & 6 & 6 & 0 & $1-2$ & 2 & 2 \\
\hline President Griepenkerl & 6 & 5 & $5-6$ & 5 & 5 & 6 & 0 & 2 & $1-2$ & $1-2$ \\
\hline Presnell & $5-6$ & 5 & 6 & $4-5$ & 5 & $5-6$ & 0 & 2 & 1 & $1-2$ \\
\hline Prince of Wales & $6-7$ & 5 & $5-6$ & 5 & $5-6$ & $5-6$ & 0 & 3 & $2-3$ & 2 \\
\hline Princess of Wales & $6-7$ & 5 & 5 & 5 & $5-6$ & $5-6$ & 0 & 3 & $2-3$ & $1-2$ \\
\hline Prolific & 5 & $4-5$ & 6 & 5 & $5-6$ & 6 & 0 & 1 & $1-2$ & 1 \\
\hline Proskaui & 5 & $4-5$ & $5-6$ & 4 & 5 & 5 & 0 & $1-2$ & $1-2$ & 1 \\
\hline Pulchra & $5-6$ & 5 & $6-7$ & 5 & 5 & 6 & 0 & 3 & 2 & 2 \\
\hline Pusisstij Rannij & 5 & 4 & 5 & 4 & $5-6$ & 5 & $0-1$ & 2 & 2 & $1-2$ \\
\hline Pussistij Rozovij & 5 & 4 & 5 & 4 & $5-6$ & 5 & $0-1$ & 2 & 3 & $1-2$ \\
\hline Quette & 6 & 5 & $5-6$ & $4-5$ & 6 & 6 & 0 & 2 & 2 & $2-3$ \\
\hline Ramos & $6-7$ & $4-5$ & 6 & 5 & 5 & $5-6$ & 0 & $2-3$ & $2-3$ & 2 \\
\hline Rariton Rose & $5-6$ & $4-5$ & $5-6$ & 5 & $5-6$ & $5-6$ & 0 & 2 & 2 & 2 \\
\hline Ray & $5-6$ & 5 & $5-6$ & 5 & 6 & 6 & 0 & 2 & 2 & $1-2$ \\
\hline
\end{tabular}




\begin{tabular}{|c|c|c|c|c|c|c|c|c|c|c|}
\hline Raymaekers & 5 & 4 & 5 & $4-5$ & 5 & $5-6$ & 0 & $2-3$ & 2 & $2-3$ \\
\hline Raymond Gaujard & $5-6$ & 5 & 5 & 5 & $5-6$ & $5-6$ & 0 & $2-3$ & 2 & 2 \\
\hline Red Bud & 6 & 5 & $5-6$ & $4-5$ & $5-6$ & 6 & 0 & 3 & $2-3$ & 2 \\
\hline Red Cheek Melocoton & 6 & 5 & 6 & 5 & $5-6$ & $5-6$ & 0 & $1-2$ & 2 & 2 \\
\hline Red Gold & $5-6$ & $4-5$ & $5-6$ & 5 & 6 & 6 & 0 & 2 & 2 & $1-2$ \\
\hline Red June & $5-6$ & $4-5$ & 6 & $4-5$ & 5 & $5-6$ & 0 & 2 & 1 & $2-3$ \\
\hline Red Magdalene & $5-6$ & $4-5$ & $5-6$ & 5 & 6 & 6 & 0 & $1-2$ & $1-2$ & $1-2$ \\
\hline Red River & $6-7$ & 4 & 5 & $4-5$ & $5-6$ & 5 & 0 & 2 & 2 & 2 \\
\hline Red Rose & $6-7$ & 5 & 6 & $4-5$ & $5-6$ & $5-6$ & 0 & 2 & 2 & 2 \\
\hline Red Shedow & $5-6$ & 5 & $6-7$ & $4-5$ & $5-6$ & $5-6$ & 0 & 2 & 2 & 2 \\
\hline Redcal & 5 & 5 & $5-6$ & 5 & 6 & 6 & 0 & $2-3$ & 2 & $2-3$ \\
\hline Redcap & $5-6$ & $4-5$ & 5 & 5 & $5-6$ & $5-6$ & 0 & 2 & 2 & 2 \\
\hline Redcrest & $5-6$ & 5 & 6 & $4-5$ & 6 & 6 & 0 & 2 & 2 & 2 \\
\hline Redelberta & 5 & 5 & 5 & $4-5$ & $5-6$ & $5-6$ & 0 & $1-2$ & 2 & $2-2$ \\
\hline Redglobe & $5-6$ & $5-$ & 6 & 5 & 5 & 6 & $0-1$ & 1 & 1 & 2 \\
\hline Redhaven & $5-6$ & $4-5$ & $6-7$ & $4-5$ & 5 & 6 & 0 & 2 & $1-2$ & $1-2$ \\
\hline Redleaf & $5-6$ & $4-5$ & $5-6$ & $4-5$ & 6 & $5-6$ & 0 & 2 & 2 & 1 \\
\hline Redskin & 6 & 4 & 6 & $4-5$ & 5-6 & $5-6$ & 0 & $2-3$ & 2 & $2-3$ \\
\hline Redtop & $5-6$ & $4-5$ & 6 & 5 & $5-6$ & $5-6$ & 0 & 2 & 2 & 2 \\
\hline Redwing & 6-7 & $4-5$ & $5-6$ & 4 & 6 & 6 & 0 & 2 & 2 & 2 \\
\hline Reeves & $5-6$ & 5 & $5-6$ & 5 & $5-6$ & $5-6$ & 0 & $1-2$ & $1-2$ & $1-2$ \\
\hline Regal Grand & 6 & 5 & 6 & 5 & $5-6$ & 6 & 0 & $1-2$ & 2 & 2 \\
\hline Regina & $5-6$ & $4-5$ & $6-7$ & 5 & $5-6$ & $5-6$ & 0 & 2 & 2 & $1-2$ \\
\hline Remény & $5-6$ & 4 & $6-7$ & 5 & 5 & $5-6$ & 0 & $2-3$ & 2 & 2 \\
\hline Ribet & 5 & 4 & 5 & 4 & 5 & 5 & 0 & $2-3$ & 2 & 1 \\
\hline Rich Lady & $6-7$ & $4-5$ & 6 & 5 & 6 & 6 & 0 & 2 & $2-3$ & 2 \\
\hline Richhaven & 5 & $4-5$ & $5-6$ & $4-5$ & $5-6$ & $5-6$ & 0 & 3 & 2 & 2 \\
\hline Rita Star & 6 & 5 & 6 & 5 & 6 & 6 & 0 & $2-3$ & 2 & 2 \\
\hline Riverdale & $5-6$ & 4 & 5 & $4-5$ & $5-6$ & $5-6$ & $0-1$ & 2 & 2 & 2 \\
\hline Rivers & 5 & $4-5$ & 6 & $4-5$ & 6 & $5-6$ & 0 & 2 & 2 & $1-2$ \\
\hline Rivers Early & 5 & $4-5$ & $5-6$ & 5 & 5-6 & 6 & 0 & 3 & 2 & 2 \\
\hline Rives Plate & 6 & 5 & $5-6$ & 5 & $5-6$ & 5 & 0 & $1-2$ & $1-2$ & 2 \\
\hline Roberta & 6 & 5 & 6 & $4-5$ & 5 & $5-6$ & 0 & 2 & 2 & $2-3$ \\
\hline Robin & 5 & 4 & 5 & $4-5$ & 5-6 & 5 & 0 & 1 & 2 & 2 \\
\hline Rochester & 6 & $4-5$ & 6 & $4-5$ & $5-6$ & $5-6$ & 0 & $1-2$ & $1-2$ & $2-3$ \\
\hline Rogue Rio & $6-7$ & 5 & $6-7$ & 5 & 6 & 6 & 0 & $2-3$ & 2 & 2 \\
\hline Romance & 5 & 5 & 6 & 5 & 6 & $5-6$ & 0 & 2 & 2 & $1-2$ \\
\hline Roquata Galet 152 & $6-7$ & 5 & $6-7$ & 5 & 6 & 6 & 0 & $2-3$ & 2 & 2 \\
\hline Rosebud & $5-6$ & $4-5$ & 6 & $4-5$ & $5-6$ & $5-6$ & 0 & 2 & 2 & $1-2$ \\
\hline Roslyn & 5 & 4 & $5-6$ & 4 & 5 & 5 & 0 & $1-2$ & $1-2$ & 1 \\
\hline Rossanna & $6-7$ & 5 & 6 & $4-5$ & $5-6$ & 6 & $0-1$ & $1-2$ & 2 & 2 \\
\hline Rosy & $6-7$ & 5 & $5-6$ & 5 & 6 & 6 & 0 & 2 & 2 & 2 \\
\hline Roter Kaiser & 5 & $4-5$ & 6 & $4-5$ & 5 & 5 & $0-1$ & $2-3$ & $1-2$ & 1 \\
\hline Rouge Julien & 6 & 5 & $5-6$ & 5 & 6 & $5-6$ & 0 & 1 & 2 & $1-2$ \\
\hline Roussanne No. 1 & $5-6$ & 5 & $6-7$ & $4-5$ & 5-6 & 6 & 0 & 1 & 2 & 2 \\
\hline Royal Ellberta & $5-6$ & $4-5$ & 6 & $4-5$ & $5-6$ & $5-6$ & 0 & $1-2$ & $1-2$ & $2-3$ \\
\hline Royal Flame & $5-6$ & 5 & $5-6$ & 5 & 5 & 6 & 0 & 2 & 2 & 2 \\
\hline Royal Gem & $5-6$ & 5 & 6 & $4-5$ & 5 & 5 & 0 & 2 & $1-2$ & 2 \\
\hline Royal George & 5 & $4-5$ & $5-6$ & 5 & 6 & 6 & 0 & 2 & 2 & 1 \\
\hline Royal Glory & $5-6$ & 5 & 6 & $4-5$ & 6 & 5 & 0 & $1-2$ & 2 & 2 \\
\hline Royal Grand & $6-7$ & $4-5$ & $6-7$ & 5 & $6-7$ & 6 & 0 & 3 & $2-3$ & 2 \\
\hline Royalvee & 6 & 5 & 6 & 5 & 6 & 5 & 0 & 2 & $1-2$ & 2 \\
\hline Rubidoux & $5-6$ & 5 & $5-6$ & 4 & $5-6$ & 5 & 0 & $2-3$ & 2 & 2 \\
\hline Rubinovüj-9 & 5 & 5 & $5-6$ & 5 & 5 & $5-6$ & $0-1$ & 2 & 1 & $1-2$ \\
\hline Russkij Kasavec & 5 & 4 & 5 & 5 & 5 & 5 & $0-1$ & 2 & $1-2$ & $1-2$ \\
\hline Rutgers Green Leaf & 6 & $4-5$ & $5-6$ & 5 & $5-6$ & 5 & 0 & $1-2$ & 2 & 2 \\
\hline Rutgers Red Leaf & $5-6$ & $4-5$ & $5-6$ & 5 & $5-6$ & $5-6$ & 0 & $1-2$ & 1 & 1 \\
\hline Saint-Martory & 6 & 5 & 6 & 5 & 6 & 6 & 0 & 2 & 2 & 1 \\
\hline Salberta & 5 & $4-5$ & 5 & $4-5$ & $5-6$ & $5-6$ & 0 & 2 & 2 & 2 \\
\hline Salwey & $5-6$ & $4-5$ & $5-6$ & $4-5$ & 6 & 6 & 0 & $1-2$ & 2 & 2 \\
\hline
\end{tabular}




\begin{tabular}{|c|c|c|c|c|c|c|c|c|c|c|}
\hline Sam Houston & $5-6$ & 5 & $5-6$ & 5 & 6 & 6 & 0 & $2-3$ & $2-3$ & 3 \\
\hline San Grand & 6 & 5 & 6 & 5 & 5 & $5-6$ & 0 & 2 & 2 & 2 \\
\hline Sanders & $5-6$ & $4-5$ & 5 & 4 & 5 & $5-6$ & 0 & 2 & $2-3$ & 1 \\
\hline Sanghaj & 6 & 5 & $6-7$ & 5 & 6 & 6 & 0 & $2-3$ & 2 & $2-3$ \\
\hline Sanguine & 6 & 5 & 6 & 5 & $6-7$ & $5-6$ & 0 & 2 & 2 & 2 \\
\hline Saturn & 6 & 5 & $5-6$ & 5 & 6 & $5-6$ & 0 & 2 & $2-3$ & $2-3$ \\
\hline Schumaker & 5 & $4-5$ & 5 & $4-5$ & 5 & 5 & 0 & 2 & 2 & $1-2$ \\
\hline Schwetzer & 5 & 4 & 5 & 5 & 5 & 6 & 0 & $1-2$ & 2 & 2 \\
\hline September Grand & $5-6$ & 5 & 6 & $4-5$ & 5 & $5-6$ & 0 & 2 & $2-3$ & $2-3$ \\
\hline Sequoia & $5-6$ & 5 & $5-6$ & 5 & 6 & $5-6$ & 0 & 2 & 2 & 2 \\
\hline Shamel & 6 & $4-5$ & $5-6$ & $4-5$ & $5-6$ & $5-6$ & $0-1$ & 2 & 2 & 2 \\
\hline Sharbati & 5 & $4-5$ & $6-7$ & 5 & 6 & 5 & 0 & 2 & $1-2$ & $1-2$ \\
\hline Sharon & $5-6$ & 5 & 6 & 5 & $6-7$ & 6 & 0 & 2 & $1-2$ & 2 \\
\hline Shasta & $6-7$ & 5 & 6 & 5 & $5-6$ & 5 & $0-1$ & $2-3$ & 2 & 2 \\
\hline Shinn & 5 & $4-5$ & 5 & $4-5$ & 5 & $5-6$ & 0 & $1-2$ & 2 & 2 \\
\hline Shipley & 6 & $4-5$ & 7 & $4-5$ & 5 & $5-6$ & $0-1$ & $1-2$ & $1-2$ & $1-2$ \\
\hline Shippers Late Red & 6 & 5 & $5-6$ & 5 & $5-6$ & 6 & 0 & $2-3$ & 2 & 2 \\
\hline Shogyku & $6-7$ & 5 & 6 & 5 & 6 & $5-6$ & 0 & $2-3$ & $2-3$ & 2 \\
\hline Short & $5-6$ & 4 & 5 & 4 & 5 & $5-6$ & 0 & 2 & $1-2$ & $1-2$ \\
\hline Siberian & 5 & 5 & 5 & $4-5$ & $5-6$ & 5 & 0 & 3 & 1 & $1-2$ \\
\hline Sierra & 6 & $4-5$ & 6 & $4-5$ & 6 & $5-6$ & 0 & 2 & 2 & 2 \\
\hline Silver Lode & 6 & 5 & $6-7$ & $4-5$ & $5-6$ & 6 & 0 & $2-3$ & $2-3$ & 2 \\
\hline Silver of Rome & $6-7$ & $4-5$ & 6 & 5 & 6-7 & 6 & 0 & 2 & 2 & 2 \\
\hline Silver Prolific & $5-6$ & $4-5$ & $5-6$ & 5 & $5-6$ & 6 & 0 & 2 & $1-2$ & 2 \\
\hline Simferopolskij Rannij & 6 & 5 & 5 & 4 & 5 & 5 & 0 & $1-2$ & 2 & $1-2$ \\
\hline Sims & 5 & 4 & 5 & $4-5$ & $5-6$ & $5-6$ & 0 & 2 & 2 & 2 \\
\hline Sixty-Six & 6 & $4-5$ & $5-6$ & 5 & $5-6$ & 6 & 0 & 2 & $2-3$ & 2 \\
\hline Sleeper Dwarf & $6-7$ & 5 & 6 & 5 & 6 & 6 & 0 & $1-2$ & $1-2$ & $1-2$ \\
\hline Smith & 5 & 4 & 5 & $4-5$ & 5 & $5-6$ & 0 & 2 & 2 & 2 \\
\hline Smock & 6 & 5 & 6 & 5 & $5-6$ & 5 & 0 & 1 & $1-2$ & 1 \\
\hline Sneed & $5-6$ & 5 & 6 & $4-5$ & 5 & 6 & 0 & 2 & 2 & 2 \\
\hline Snow Queen & $6-7$ & 4 & 6 & 5 & $5-6$ & 6 & 0 & $2-3$ & 2 & 2 \\
\hline Socala & $6-7$ & 5 & $5-6$ & 5 & 6 & 6 & 0 & 2 & $2-3$ & 2 \\
\hline Sočnij & 5 & 4 & 5 & $4-5$ & 5 & 5 & 0 & $1-2$ & 3 & 3 \\
\hline Solo & $5-6$ & 5 & $5-6$ & $4-5$ & 6 & 6 & 0 & 1 & $1-2$ & 2 \\
\hline Somervee & $5-6$ & 5 & 5 & $4-5$ & 5 & $5-6$ & 0 & $1-2$ & 2 & 2 \\
\hline Southland & $5-6$ & $4-5$ & 6 & 5 & 5 & 6 & $0-1$ & 2 & $1-2$ & 2 \\
\hline Spotlight & 6 & 5 & 5 & 5 & $5-6$ & 6 & 0 & 2 & 2 & 2 \\
\hline Spring Red & 6 & $4-5$ & $5-6$ & 5 & $5-6$ & 5 & 0 & $1-2$ & 3 & $1-2$ \\
\hline Springcrest & $6-7$ & 5 & $6-7$ & $4-5$ & $5-6$ & $5-6$ & 0 & 3 & 2 & 2 \\
\hline Springgold & $6-7$ & 5 & 6 & $4-5$ & 5 & 6 & 0 & 2 & 2 & 1 \\
\hline Springlady & $6-7$ & $5-6$ & $6-7$ & 5 & $5-6$ & 5 & 0 & 2 & $1-2$ & 2 \\
\hline Springtime & $5-6$ & 5 & 6 & 5 & 5 & $5-6$ & 0 & $2-3$ & 2 & 2 \\
\hline St. John & 5 & $4-5$ & 5 & 5 & 5 & 5 & $0-1$ & 3 & $2-3$ & 2 \\
\hline Stanford & 5 & 5 & $5-6$ & 5 & 5 & $5-6$ & 0 & 2 & 2 & 2 \\
\hline Starcrest & $5-6$ & 5 & 5 & $4-5$ & 6 & 5 & 0 & $1-2$ & $1-2$ & $1-2$ \\
\hline Stark Delicious & 5 & $4-5$ & 5 & 5 & $5-6$ & 5 & 0 & 2 & $2-3$ & 2 \\
\hline Stark EarliGko & 6 & 5 & $5-6$ & 5 & 5 & $5-6$ & 0 & 3 & 2 & $2-3$ \\
\hline Stark Late Gold & $5-6$ & $4-5$ & $5-6$ & $4-5$ & $5-6$ & 5 & 0 & 2 & 2 & 2 \\
\hline Stark Redgold & $5-6$ & 5 & $5-6$ & 5 & 6 & $5-6$ & 0 & 2 & $1-2$ & 3 \\
\hline Stark SunGlo & 5 & 5 & 6 & 5 & 6 & 5 & 0 & 2 & 2 & 2 \\
\hline Stark Sure Crop & 5 & 5 & 5 & 5 & $5-6$ & $5-6$ & $0-1$ & $1-2$ & $1-2$ & 2 \\
\hline Starking Delicous & $5-6$ & 5 & $5-6$ & 5 & $5-6$ & 6 & 0 & 2 & 2 & 2 \\
\hline Steadley & 5 & $4-5$ & 5 & $4-5$ & $5-6$ & 5 & 0 & $2-3$ & 2 & $1-2$ \\
\hline Stephenson & $5-6$ & 4 & 5 & 4 & 5 & 5 & 0 & 2 & 2 & 2 \\
\hline Stevens & $5-6$ & 5 & $5-6$ & $4-5$ & $5-6$ & 6 & 0 & 2 & $1-2$ & $1-2$ \\
\hline Stevens Late & 5 & $4-5$ & 5 & $4-5$ & 5 & 5 & 0 & 2 & $1-2$ & $1-2$ \\
\hline Stolovyj & 5 & 5 & 5 & $4-5$ & $5-6$ & 6 & 0 & $1-2$ & 2 & 2 \\
\hline Stonewell Jackson & $5-6$ & 5 & 6 & 5 & $5-6$ & $5-6$ & $0-1$ & 2 & 2 & 3 \\
\hline Stuart & $5-6$ & -5 & $5-6$ & $4-5$ & 5 & 6 & 0 & $1-2$ & 2 & 2 \\
\hline
\end{tabular}




\begin{tabular}{|c|c|c|c|c|c|c|c|c|c|c|}
\hline Stump & 5 & 5 & $5-6$ & 5 & 5 & $5-6$ & $0-1$ & 2 & 2 & 2 \\
\hline Sudanell & $5-6$ & 5 & 6 & 5 & $5-6$ & $5-6$ & 0 & $2-3$ & 2 & 2 \\
\hline Suka Suhék & 5 & 5 & 6 & 4 & 5 & $5-6$ & 0 & 2 & $2-3$ & 2 \\
\hline Sullivan & 6 & $4-5$ & $5-6$ & $4-5$ & $5-6$ & 6 & 0 & $1-2$ & $1-2$ & $1-2$ \\
\hline Sullivan Elberta & 5 & $4-5$ & $5-6$ & 5 & 6 & 6 & 0 & 2 & 2 & $1-2$ \\
\hline Summer Heath & 5 & 5 & 6 & $4-5$ & 5 & $5-6$ & 0 & 2 & 2 & 2 \\
\hline Summer Snow & 5 & $4-5$ & $5-6$ & 5 & $5-6$ & 5 & 0 & 2 & $1-2$ & $1-2$ \\
\hline Summerbrite & $5-6$ & 5 & 6 & $4-5$ & $5-6$ & 6 & 0 & 2 & 2 & 2 \\
\hline Summercrest & $6-7$ & $4-5$ & $5-6$ & $4-5$ & $5-6$ & $5-6$ & 0 & $1-2$ & 2 & 2 \\
\hline Summerland & 6 & 5 & 6 & 5 & $5-6$ & 6 & 0 & 3 & 2 & 3 \\
\hline Summerlong & $5-6$ & 5 & $5-6$ & 5 & $5-6$ & $5-6$ & 0 & $1-2$ & 2 & 2 \\
\hline Summertime & 5 & $4-5$ & $6-7$ & 5 & 5 & $6-7$ & $0-1$ & 1 & $1-2$ & 3 \\
\hline Sun Cling & $5-6$ & 5 & 6 & 5 & 6 & 6 & 0 & 2 & 2 & 2 \\
\hline Sun Grand & $6-7$ & 5 & 6 & $4-5$ & $6-7$ & 7 & 0 & $2-3$ & $2-3$ & 2 \\
\hline Sunbeam & $5-6$ & $4-5$ & $6-7$ & $4-5$ & $5-6$ & 6 & 0 & $1-2$ & 3 & 2 \\
\hline Sunbright & 5 & $4-5$ & -6 & 5 & 6 & $5-6$ & 0 & 1 & 2 & $2-3$ \\
\hline Suncrest & 7 & 5 & 6 & $4-5$ & 5 & $5-6$ & 0 & 2 & 2 & 2 \\
\hline Suncrest 1 & 5 & 5 & $5-6$ & 5 & 6 & 6 & 0 & $1-2$ & 1 & $2-3$ \\
\hline Sunday & $5-6$ & 5 & 6 & $4-5$ & $5-6$ & 6 & 0 & $2-3$ & 2 & 3 \\
\hline Sunglow & 6 & 4 & $5-6$ & $4-5$ & 6 & $5-6$ & 0 & 2 & 2 & 2 \\
\hline Sungold & 7 & $4-5$ & 5 & 55 & $5-6$ & 6 & $0-1$ & $1-2$ & 1 & 2 \\
\hline Sungrand & 6 & $4-5$ & 5 & $4-5$ & 6 & $5-6$ & 0 & 1 & 2 & 2 \\
\hline Sunhaven & $5-6$ & $4-5$ & $6-7$ & $4-5$ & 5 & 6 & 0 & $1-2$ & $1-2$ & 2 \\
\hline Sunhigh & 6 & 5 & 6 & $4-5$ & 5 & $5-6$ & 0 & 2 & 2 & 1 \\
\hline Sunrise & 5 & 4 & 6 & 5 & $5-6$ & 5 & 0 & 2 & 2 & $2-3$ \\
\hline Sunshine & 6 & 5 & 5 & $4-5$ & 6 & 6 & 0 & 2 & 2 & 2 \\
\hline Super Precoce & 7 & $4-5$ & $6-7$ & 5 & 6 & $6-7$ & 0 & $1-2$ & 2 & 2 \\
\hline Supercrimson & $5-6$ & $4-5$ & 6 & 5 & 6 & 6 & 0 & $1-2$ & 1 & 2 \\
\hline Suppan Duránci & 5 & 4 & $5-6$ & $4-5$ & $5-6$ & $5-6$ & 0 & $2-3$ & $1-2$ & $2-3$ \\
\hline Surabian & 6 & 5 & $5-6$ & $4-5$ & 6 & $5-6$ & 0 & 2 & 2 & 2 \\
\hline Sure Crop & 5 & 5 & $5-6$ & $4-5$ & $5-6$ & $5-6$ & 0 & 3 & 2 & $2-3$ \\
\hline Surpasse & $5-6$ & $4-5$ & 6 & 5 & $5-6$ & 6 & 0 & $2-3$ & 2 & 2 \\
\hline Surprise & 6 & 5 & $6-7$ & 5 & 6 & $5-6$ & 0 & $1-2$ & $1-2$ & 2 \\
\hline Suzanne Darnon & $5-6$ & $4-5$ & 6 & 4 & $5-6$ & $5-6$ & 0 & $2-3$ & 2 & $1-2$ \\
\hline Sweet Lady & 6 & 5 & 5 & 5 & 6 & $5-6$ & 0 & 2 & 2 & 2 \\
\hline Szatymazi Ford & 5 & 4 & $5-6$ & $4-5$ & $5-6$ & 5 & $0-1$ & $1-2$ & 2 & $1-2$ \\
\hline Szatymazi Győztes & 5 & 4 & 5 & 4 & $5-6$ & 5 & $0-1$ & $1-2$ & $1-2$ & $1-2$ \\
\hline Szegedi arany & $5-6$ & $4-5$ & 6 & 5 & $5-6$ & $5-6$ & 0 & 2 & $1-2$ & 2 \\
\hline Szép Örnő & $5-6$ & 5 & $5-6$ & 5 & 6 & 5 & 0 & $2-3$ & $2-3$ & 2 \\
\hline Szöghi duráncija & $5-6$ & 5 & 6 & 5 & $5-6$ & 5 & 0 & $1-2$ & $1-2$ & $1-2$ \\
\hline Takakura & 6 & 5 & 6 & $4-5$ & 5 & 6 & 0 & $2-3$ & 2 & 2 \\
\hline Tardiv Valla & 6 & $4-5$ & $6-7$ & 5 & 6 & $5-6$ & 0 & 2 & 2 & $2-3$ \\
\hline Tatura Down & $6-7$ & 5 & 7 & 5 & $5-6$ & $5-6$ & 0 & $2-3$ & 2 & 2 \\
\hline Tena & $5-6$ & $4-5$ & $5-6$ & $4-5$ & $5-6$ & $5-6$ & 0 & 2 & 2 & 2 \\
\hline Terry & 5 & 4 & $5-6$ & 4 & $5-6$ & 6 & 0 & 2 & $1-2$ & $1-2$ \\
\hline Téton de Venus & 6 & 5 & 7 & 5 & 6 & $5-6$ & 0 & 3 & 2 & 2 \\
\hline Thomas Rivers & $5-6$ & $4-5$ & $5-6$ & 4 & 5 & $5-6$ & 0 & $1-2$ & $1-2$ & $1-2$ \\
\hline Thurber & 5 & $4-5$ & 6 & $4-5$ & $5-6$ & $5-6$ & $0-1$ & 2 & $1-2$ & 2 \\
\hline Tokane & 6 & 5 & 6 & $4-5$ & $5-6$ & 6 & 0 & 2 & 2 & 2 \\
\hline Toledo & $6-7$ & 5 & $6-7$ & 5 & 6 & 6 & $0-1$ & 2 & $1-2$ & 2 \\
\hline Toreador & $6-7$ & 5 & $5-6$ & $4-5$ & 6 & $5-6$ & 0 & 2 & 2 & 2 \\
\hline Transvaal & $5-6$ & 4 & 5 & 4 & $5-6$ & $5-6$ & 0 & $1-2$ & $1-2$ & 2 \\
\hline Tremmel & 5 & $4-5$ & $5-6$ & 5 & 5 & 5 & 0 & 1 & 1 & $1-2$ \\
\hline Triana & 6 & 5 & $5-6$ & 5 & 6 & 5 & 0 & 2 & 2 & $1-2$ \\
\hline Triestina & 6 & $4-5$ & 6 & $4-5$ & 7 & 6 & 0 & $2-3$ & 2 & $2-3$ \\
\hline Triogem & $6-7$ & 5 & 6 & 5 & 5 & 6 & 0 & 1 & $1-2$ & $2-3$ \\
\hline Trionfo Liscio & $5-6$ & 5 & $6-7$ & 5 & 7 & 6 & 0 & 3 & $2-3$ & 2 \\
\hline Triumph & 5 & $4-5$ & 6 & 5 & $5-6$ & 5 & 0 & 1 & $1-2$ & $1-2$ \\
\hline Tropico & $6-7$ & 5 & 7 & 5 & 6 & $5-6$ & 0 & 3 & $2-3$ & 2 \\
\hline Troth & 5 & $4-5$ & $5-6$ & 4 & $5-6$ & 5 & $0-1$ & 2 & 2 & 2 \\
\hline
\end{tabular}




\begin{tabular}{|c|c|c|c|c|c|c|c|c|c|c|}
\hline Troubador & $5-6$ & $4-5$ & 6 & 5 & 5 & 6 & 0 & $1-2$ & 2 & $2-3$ \\
\hline Tudor & 5 & 4 & $5-6$ & $4-5$ & $5-6$ & $5-6$ & 0 & $2-3$ & 2 & 2 \\
\hline Tuirbull Cling & $5-6$ & $4-5$ & $5-6$ & $4-5$ & 5 & 5 & 0 & 2 & $1-2$ & 1 \\
\hline Tulip & 7 & 5 & $6-7$ & 5 & $5-6$ & $5-6$ & 0 & 2 & 2 & 2 \\
\hline Tuscan & $6-7$ & 5 & 6 & 5 & & 6 & 0 & 3 & $2-3$ & $1-2$ \\
\hline Unique & 5 & $4-5$ & 5 & $4-5$ & $5-6$ & $5-6$ & 0 & $2-3$ & 2 & 2 \\
\hline Valdero & 6 & 5 & 6 & 5 & 5 & 6 & 0 & $2-3$ & 2 & 2 \\
\hline Valerij Tčkalov & $5-6$ & 5 & 5 & $4-5$ & 5 & 6 & $0-1$ & $1-2$ & 2 & 2 \\
\hline Van Riebeeck & 6 & $4-5$ & $5-6$ & $4-5$ & 5 & $5-6$ & 0 & 2 & $1-2$ & $1-2$ \\
\hline Vanderpoole & $5-6$ & $4-5$ & 5 & 5 & $5-6$ & 6 & 0 & 2 & 2 & $1-2$ \\
\hline Vanguard & 6 & $4-5$ & $5-6$ & $4-5$ & $5-6$ & 6 & 0 & 2 & $2-3$ & 2 \\
\hline Vaughan & $5-6$ & $4-5$ & 6 & 5 & 6 & $5-6$ & $0-1$ & $2-3$ & 2 & 2 \\
\hline Vedette Abricotée & 6-7 & 5 & $6-7$ & 5 & 6 & 6 & 0 & 3 & 2 & $1-2$ \\
\hline Vedoka & 5 & 5 & 6 & 5 & 5 & $5-6$ & 0 & $1-2$ & 1 & $1-2$ \\
\hline Veefreese & 5 & 5 & $5-6$ & 5 & 6 & 5 & $0-1$ & 2 & 2 & $1-2$ \\
\hline Vega & 6 & $4-5$ & 6 & 5 & 6 & 6 & 0 & $2-3$ & 2 & 2 \\
\hline Ventura & $5-6$ & 5 & $6-7$ & 5 & $5-5$ & 6 & 0 & 2 & $2-3$ & 2 \\
\hline Venus & 6 & $4-5$ & 6 & $4-5$ & $5-6$ & $5-6$ & 0 & $2-3$ & 2 & $1-2$ \\
\hline Vérbarack & 7 & 5 & 6 & 5 & 5 & 5 & 0 & $2-3$ & $2-3$ & 3 \\
\hline Vesuvio & 6 & 5 & 6 & 5 & 5 & 6 & 0 & $1-2$ & $2-3$ & $1-2$ \\
\hline Veteran & $5-6$ & $4-5$ & 5 & 5 & 6 & $5-6$ & 0 & 2 & 1 & 2 \\
\hline Vezerle duráncija & 5 & $4-5$ & $5-6$ & $4-5$ & 5 & 6 & $0-1$ & $1-2$ & $1-2$ & $1-2$ \\
\hline Vimy & $5-6$ & $4-5$ & 6 & 5 & $5-6$ & 5 & 0 & 2 & 2 & 2 \\
\hline Vineland & 5 & $4-5$ & $5-6$ & $4-5$ & 5 & $5-6$ & 0 & 2 & $1-2$ & $2-3$ \\
\hline Violet & 6-7 & 5 & $6-7$ & 5 & 6 & 6 & 0 & 2 & 2 & $2-3$ \\
\hline Vivian & 6-7 & 5 & 6 & 5 & $5-6$ & $5-6$ & 0 & 2 & $1-2$ & 2 \\
\hline Vivid Globe & $5-6$ & $4-5$ & $5-6$ & 5 & 5 & 6 & 0 & 2 & 2 & $1-2$ \\
\hline Vladimir & 5 & $4-5$ & $5-6$ & $4-5$ & 6 & 6 & 0 & $1-2$ & $1-2$ & 2 \\
\hline Vystavočnij & 5 & $4-5$ & 6 & $4-5$ & 5 & 5 & $0-1$ & 2 & 1 & 1 \\
\hline Waddell & $5-6$ & 5 & $5-6$ & 5 & 6 & $5-6$ & 0 & 2 & 2 & 2 \\
\hline Wager & 5 & 5 & 6 & 5 & $5-6$ & 6 & 0 & $1-2$ & 2 & 2 \\
\hline Waldon & $5-6$ & $4-5$ & $5-6$ & 5 & 6 & 5 & 0 & $2-3$ & 2 & 2 \\
\hline Walgant & $5-6$ & 5 & 6 & $4-5$ & $5-6$ & $5-6$ & 0 & 2 & 2 & 3 \\
\hline Walter & $5-6$ & $4-5$ & $5-6$ & 5 & 6 & 5 & 0 & 2 & $1-2$ & $2-3$ \\
\hline Wandell & $5-6$ & $4-5$ & 6 & $4-5$ & 6 & 5 & 0 & 2 & 2 & 2 \\
\hline Ward Late & 5 & $4-5$ & 5 & $4-5$ & 5 & $5-6$ & 0 & 2 & $1-2$ & $1-2$ \\
\hline Warden & $5-6$ & 5 & $6-6$ & 5 & 6 & 6 & 0 & 2 & 2 & 2 \\
\hline Washington & 7 & 5 & 6 & 5 & $5-6$ & $5-6$ & 0 & 3 & $2-3$ & 2 \\
\hline Waterloo & $5-6$ & $4-5$ & 7 & $4-5$ & $5-6$ & 6 & 0 & $2-3$ & 2 & 2 \\
\hline Weinberger & 7 & 5 & 7 & 5 & 6 & 6 & 0 & $2-3$ & 2 & 2 \\
\hline Welberta & $5-6$ & 5 & $5-6$ & 5 & $5-6$ & 6 & 0 & 2 & 2 & 2 \\
\hline Welcome & 5 & $4-5$ & 6 & 5 & $5-6$ & $5-6$ & 0 & 2 & 2 & $1-2$ \\
\hline Weldon & 5 & $4-5$ & $5-6$ & $4-5$ & 6 & $5-6$ & $0-1$ & 2 & $2-3$ & 2 \\
\hline Western Pride & 5 & 5 & 6 & $4-5$ & 6 & 6 & 0 & $1-2$ & 2 & $2-3$ \\
\hline Wheatland & 5 & 5 & $5-6$ & 5 & $5-6$ & $5-6$ & 0 & 3 & 2 & 2 \\
\hline Wheeler & $5-6$ & $4-5$ & 6 & $4-5$ & 6 & $5-6$ & 0 & 2 & 2 & 2 \\
\hline White Hale & 5 & $4-5$ & $5-6$ & 5 & 6 & 6 & 0 & $2-3$ & $2-3$ & 2 \\
\hline White Imperial & $6-7$ & 5 & 6 & 5 & $5-6$ & 6 & 0 & $2-3$ & 2 & $2-3$ \\
\hline White Lady & $5-6$ & 5 & $5-6$ & 5 & 6 & $5-6$ & 0 & 2 & 2 & 2 \\
\hline White Magdalene & 5 & $4-5$ & $6-7$ & $4-5$ & 6 & 6 & 0 & 2 & $1-2$ & $1-2$ \\
\hline White Rose & $6-7$ & $4-5$ & $5-6$ & 5 & $5-6$ & 6 & 0 & 2 & 2 & 2 \\
\hline Wickersham & 5 & 5 & 5 & 5 & 6 & 6 & 0 & $1-2$ & 1 & 2 \\
\hline Wiggins & 5 & $4-5$ & $5-6$ & 5 & 6 & $5-6$ & 0 & 2 & $2-3$ & 2 \\
\hline Wilder & $5-6$ & 4 & 6 & $4-5$ & $5-6$ & $5-6$ & 0 & $1-2$ & 2 & $2-3$ \\
\hline Wildrose & 5 & 5 & 6 & 5 & $5-6$ & 6 & $0-1$ & 1 & $2-3$ & 2 \\
\hline Willett & $5-6$ & $4-5$ & $5-6$ & $4-5$ & 6 & $5-6$ & 0 & 2 & 2 & 2 \\
\hline Williams Gem & 5 & 5 & $6-7$ & 5 & $5-6$ & $5-6$ & 0 & $2-3$ & $2-3$ & 2 \\
\hline Wilma & 5 & $4-5$ & 6 & $4-5$ & 6 & $5-6$ & 0 & $1-2$ & 1 & $1-2$ \\
\hline Wilmer & 5 & $4-5$ & $5-6$ & 5 & 6 & 66 & 0 & 2 & 2 & 2 \\
\hline Wiser & $6-7$ & $4-5$ & 6 & 5 & $5-6$ & $5-6$ & 0 & $2-3$ & $1-2$ & 2 \\
\hline
\end{tabular}




\begin{tabular}{|l|c|c|c|c|c|c|c|c|c|c|}
\hline Wooster & 5 & 5 & $5-6$ & $4-5$ & 6 & 6 & 0 & 2 & 2 & 2 \\
\hline Württenberg király & 5 & 4 & 5 & 5 & $5-6$ & $5-6$ & 0 & 1 & $1-2$ & $1-2$ \\
\hline Yakima Hale & $5-6$ & $4-5$ & $5-6$ & $4-5$ & 6 & $5-6$ & $0-1$ & 2 & 2 & 2 \\
\hline Yellow Admirable & 6 & 5 & $6-7$ & 5 & 6 & 6 & 0 & 2 & 2 & 2 \\
\hline Yellow Free & $5-6$ & 5 & 6 & 5 & 6 & 6 & 0 & 2 & 2 & 2 \\
\hline Yellow Globe & 5 & 5 & $5-6$ & 5 & $5-6$ & 6 & 0 & 2 & $1-2$ & 2 \\
\hline Yellow Hobson & 5 & 5 & $6-7$ & $4-5$ & $5-6$ & $5-6$ & 0 & $1-2$ & $1-2$ & $1-2$ \\
\hline Yelo & $6-7$ & 5 & 5 & 5 & 6 & $5-6$ & 0 & 2 & $1-2$ & 2 \\
\hline Yelow Rarekipe & $5-6$ & 5 & $6-7$ & 5 & 6 & 5 & 0 & 3 & $2-3$ & $1-2$ \\
\hline Young's Cling & 6 & $4-5$ & 6 & $4-5$ & $5-6$ & 6 & 0 & 2 & 2 & 2 \\
\hline Yunnan & $6-7$ & $4-5$ & 5 & $4-5$ & 6 & 6 & $0-1$ & $1-2$ & 1 & 2 \\
\hline Zafrani Pozdnij & 5 & 5 & 5 & $4-5$ & 5 & 5 & 0 & 2 & $1-2$ & 2 \\
\hline Zafrani Srednij & 5 & $4-5$ & 5 & $4-5$ & 5 & 5 & 0 & 2 & 2 & 2 \\
\hline Zaidulab & 7 & 5 & $6-7$ & 5 & 6 & $5-6$ & 0 & 2 & $1-2$ & $1-2$ \\
\hline Žemčužina & 5 & $4-5$ & 5 & $4-5$ & $5-6$ & 5 & $0-1$ & 1 & 2 & 2 \\
\hline Zlatan Jubilif & $5-6$ & $4-5$ & 5 & $4-5$ & 5 & 5 & 0 & $1-2$ & 2 & 2 \\
\hline Zoletij & 5 & $4-5$ & 5 & $4-5$ & 5 & 5 & 0 & $1-2$ & 2 & 2 \\
\hline Zuni & $5-6$ & $4-5$ & 5 & $4-5$ & 5 & 6 & 0 & 2 & 2 & $1-2$ \\
\hline
\end{tabular}

Table 2. Relative ecological and biological indicator values of peach cultivars.

\begin{tabular}{|c|c|c|c|}
\hline Relative indicator values & Interval & Mean & CV., \\
\hline \multicolumn{4}{|l|}{ TOGETHER $(\mathrm{n}=700)$} \\
\hline Temperature figures (TB) & $5 \rightarrow 7$ & $5.69 \pm 0.67$ & 11.8 \\
\hline Moisture figures (WB) & $4 \rightarrow 6$ & $4.65 \pm 0.48$ & 9.7 \\
\hline Reaction figures (RB) & $4 \rightarrow 7$ & $5.78 \pm 0.64$ & 11.1 \\
\hline Nitrogen figures (NB) & $4 \rightarrow 6$ & $4.69 \pm 0.47$ & 9.9 \\
\hline Light figures (LB) & $5 \rightarrow 7$ & $5.51 \pm 0.54$ & 9.8 \\
\hline Continentality values (KB) & $5 \rightarrow 7$ & $5.65 \pm 0.58$ & 10.3 \\
\hline Salt figures $(\mathrm{SB})$ & $0 \rightarrow 1$ & $0.05 \pm 0.13$ & 260 \\
\hline Open pollination $(\mathrm{OP})$ & $1 \rightarrow 4$ & $1.94 \pm 0.82$ & 42.3 \\
\hline Frost resistance (FR) & $1 \rightarrow 3$ & $1.86 \pm 0.54$ & 29.0 \\
\hline Disease resistance (DR) & $1 \rightarrow 3$ & $1.87 \pm 0.55$ & 29.4 \\
\hline \multicolumn{4}{|l|}{ PEACH $(n=562)$} \\
\hline Temperature figures $(\mathrm{TB})$ & $5 \rightarrow 6$ & $5.49 \pm 0.47$ & 8.6 \\
\hline Moisture figures (WB) & $4 \rightarrow 6$ & $5.56 \pm 0.43$ & 7.7 \\
\hline Reaction figures (RB) & $4 \rightarrow 6$ & $5.48 \pm 0.38$ & 6.9 \\
\hline Nitrogen figures (NB) & $4 \rightarrow 6$ & $5.17 \pm 0.42$ & 8.1 \\
\hline Light figures (LB) & $5 \rightarrow 7$ & $5.57 \pm 0.43$ & 7.7 \\
\hline Continentality values $(\mathrm{KB})$ & $5 \rightarrow 7$ & $5.65 \pm 0.57$ & 9.6 \\
\hline Salt figures (SB) & $0 \rightarrow 1$ & $0.04 \pm 0.13$ & 325 \\
\hline Open pollination $(\mathrm{OP})$ & $1 \rightarrow 4$ & $2.62 \pm 0.74$ & 28.2 \\
\hline Frost resistance (FR) & $1 \rightarrow 3$ & $1.84 \pm 0.55$ & 29.9 \\
\hline Disease resistance (DR) & $1 \rightarrow 3$ & $1.78 \pm 0.49$ & 27.5 \\
\hline \multicolumn{4}{|l|}{ NECTARINE (138) } \\
\hline Temperature figures (TB) & $5 \rightarrow 7$ & $6.01 \pm 0.73$ & 12.1 \\
\hline Moisture figures (WB) & $4 \rightarrow 5$ & $4.86 \pm 0.47$ & 9.7 \\
\hline Reaction figures (RB) & $5 \rightarrow 7$ & $4.95 \pm 0.68$ & 13.7 \\
\hline Nitrogen figures (NB) & $4 \rightarrow 5$ & $4.79 \pm 0.44$ & 9.2 \\
\hline Light figures (LB) & $5 \rightarrow 7$ & $5.79 \pm 0.54$ & 9.3 \\
\hline Continentality values $(\mathrm{KB})$ & $5 \rightarrow 7$ & $5.96 \pm 0.52$ & 8.7 \\
\hline Salt figures (SB) & $0 \rightarrow 1$ & $0.07 \pm 0.31$ & 442.8 \\
\hline Open pollination $(\mathrm{OP})$ & $1 \rightarrow 3$ & $2.05 \pm 0.61$ & 29.8 \\
\hline Frost resistance $(\mathrm{FR})$ & $1 \rightarrow 3$ & $1.96 \pm 0.49$ & 25.0 \\
\hline Disease resistance (DR) & $1 \rightarrow 3$ & $2.02 \pm 0.57$ & 28.2 \\
\hline
\end{tabular}

